\title{
Aplicación del régimen administrativo especial de los fondos Next Generation EU a las entidades locales ${ }^{1}$
}

\section{Application of the special administrative laws for the Next Generation EU funds to local governments}

\author{
Francisco Velasco Caballero \\ Universidad Autónoma de Madrid (España) \\ ORCID: https://orcid.org/0000-0003-1055-3939 \\ francisco.velasco@uam.es
}

\begin{abstract}
NOTA BIOGRÁFICA
Catedrático de Derecho administrativo. Director de Investigación del Instituto de Derecho Local de la Universidad Autónoma de Madrid. Ex Letrado del Tribunal Constitucional. Director del Anuario de Derecho Municipal y del Tratado de Derecho Local (2021). Actualmente, co-director del proyecto de investigación europeo LoGOV (Local Government and the Changing Urban-Rural Interplay: Number 823961) y del proyecto nacional PID2019-105799RB-100 (Políticas y servicios públicos contra la despoblación).
\end{abstract}

\begin{abstract}
RESUMEN
Los fondos Next Generation EU, creados por la Unión Europea para la recuperación y la transformación económica tras la epidemia de Covid-19, requieren de una ingente actividad administrativa de los Estados miembros. No sólo de la Administración estatal, sino también las Administraciones autonómicas y locales. Para la gestión de los fondos europeos, el Gobierno español ha dictado el Real Decreto-Ley 36/2020, con numerosas medidas de agilización y simplificación administrativas. El ámbito de aplicación de estas medidas es muy diverso: algunas se aplican a todas las Administraciones públicas; otras sólo a la Administración estatal. Se plantea a partir de aquí en qué medida las distintas normas del Real DecretoLey $36 / 2020$ son directa o supletoriamente aplicables a las entidades locales, cuando ejecuten proyectos financiados con los fondos Next Generation EU.
\end{abstract}

\section{PALABRAS CLAVE}

Mecanismo de Recuperación y Resiliencia de la Unión Europea; Plan de Recuperación, Transformación y Resiliencia; gestión de fondos europeos; procedimiento administrativo; entidades locales.

1 El presente estudio se ha realizado en el marco del proyecto de investigación nacional "Proyectos y políticas públicas contra la despoblación" (PID2019-105799RB100), del Ministerio de Ciencia e Innovación, y del proyecto europeo Horizon 2020 "Local Government and the Changing Urban-Rural Interplay-LoGov" (Grant Agreement number 823961).

Abreviaturas y acrónimos utilizados: EBEP: Estatuto Básico del Empleado Público; FEADER: Fondo Europeo Agrícola de Desarrollo Rural; FEDER: Fondo Europeo de Desarrollo Regional; FSE +: Fondo Social Europeo Plus; IRUE: Instrumento de Recuperación de la Unión Europea; LBRL: Ley reguladora de las Bases del Régimen Local; LCSP: Ley de Contratos del Sector Público; LGP: Ley General Presupuestarias; LHL: Ley de Haciendas Locales; LPAC: Ley de Procedimiento Administrativo Común de las Administraciones Públicas; LRJSP: Ley de Régimen Jurídico del Sector Público; MRR: Mecanismo de Recuperación y Resiliencia; NGEU: Next Generation UE; PRTR: Plan de Recuperación, Transformación y Resiliencia; RDL-PRTR: Real Decreto-ley por el que se aprueban medidas urgentes para la modernización de la Administración Pública y para la ejecución del Plan de Recuperación, Transformación y Resiliencia; PERTE: Proyecto Estratégico de Recuperación y Transformación Económica; STC: Sentencia del Tribunal Constitucional; STS: Sentencia del Tribunal Supremo; UE: Unión Europea. 


\begin{abstract}
The Next Generation EU funds, created by the European Union for the recovery and economic transformation after the Covid-19 epidemic, demand an enormous administrative activity from the Member States. Not only of the National Administration, but also of the regional and local authorities. For the management of European funds, the Spanish Government has issued Royal Decree-Law 36/2020 containing many administrative streamlining and simplification measures. The scope of these measures is very diverse: some apply to all public administrations, including the local authorities; others only to the National Administration. It arises the question, to what extent the different rules of Royal Decree-Law $36 / 2020$ are directly or indirectly applicable to local entities, when they manage projects financed with Next Generation EU funds.
\end{abstract}

\title{
KEYWORDS
}

Recovery and Resilience Mechanism of the European Union; Recovery, Transformation and Resilience Plan; management of European funds; administrative procedure; local governments.

\begin{abstract}
SUMARIO
FONDOS EUROPEOS PARA LA RECUPERACIÓN TRAS LA COVID-19 Y ESTADOS MIEMBROS. 1. EJECUCIÓN INTERNA DE LOS FONDOS EUROPEOS. 1.1. AGILIZACIÓN Y SIMPLIFICACIÓN ADMINISTRATIVA ESTATAL Y AUTONÓMICA. 1.2. PARTICIPACIÓN LOCAL EN LA GESTIÓN DEL PRTR. 1.3. PARTICIPACIÓN LOCAL EN LOS PROYECTOS ESTRATÉGICOS PARA LA RECUPERACIÓN Y TRANSFORMACIÓN ECONÓMICA. 2. APLICACIÓN A LAS ENTIDADES LOCALES DE LAS NORMAS ESPECIALES DE AGILIZACIÓN Y SIMPLIFICACIÓN ADMINISTRATIVA. 2.1. REGLAS ADMINISTRATIVAS ESTATALES. 2.2. VIGENCIA TEMPORAL. 2.3. ÁMBITOS OBJETIVOS DE APLICACIÓN. 2.4. ÁMBITOS SUBJETIVOS DE APLICACIÓN. 2.5. INTERACCIÓN ENTRE LOS CRITERIOS OBJETIVOS Y SUBJETIVOS. 3. APLICACIÓN SUPLETORIA DEL RDL-PRTR. 4. APLICACIÓN SUPLETORIA DEL DERECHO AUTONÓMICO PARA LA EJECUCIÓN LOCAL DE LOS FONDOS EUROPEOS.
\end{abstract}

\section{FONDOS EUROPEOS PARA LA RECUPERACIÓN TRAS LA COVID-19 Y ESTADOS MIEMBROS}

1. A lo largo de toda la pandemia, no sólo en su fase final, la Unión Europea ha activado varias formas financieras extraordinarias para ayudar a los Estados miembros frente a la crisis epidemiológica y sanitaria (Izquierdo, 2021, pp. 450 y 457). En la fase intermedia de la pandemia, vislumbrando ya su fin a medio plazo, la Unión Europea ha iniciado también una ambiciosa estrategia de recuperación económica. Aunque el buque insignia de esta recuperación es el novedoso Mecanismo de Recuperación y Resiliencia (MRR) dotado con 672.500 millones de euros, la estrategia europea es más completa y compleja (Pazos, 2021. p. 51).

2. En primer lugar, el Consejo Europeo de 17, 18, 19, 20 y 21 de julio de 2020 optó por una estrategia general de ayudas económicas para la recuperación, bien reforzando con nuevos recursos financieros varios fondos europeos preexistentes, bien mediante nuevos fondos. Así se plasma en el nuevo Marco Presupuestario Plurianual 2021-2027², en la modificación de la Decisión sobre el sistema de recursos propios de la UE ${ }^{3}$ (Sánchez-Barrueco, 2021, pp. 563 y 578) y en el llamado Instrumento de Recuperación de la Unión Europea o Next Generation EU (NGEU) ${ }^{4}$, del que el MRR es una pieza fundamental, aunque no la única. Así, conforme al art. 2 del Reglamento (UE) 2020/2094, el Instrumento de Recuperación de la Unión Europea (IRUE) también instrumentaliza -con nueva financiación- varios fondos estructurales o de cohesión preexistentes, como el Fondo Social Europeo Plus [FSE+] ${ }^{5}$, el Fondo Europeo de Desarrollo Regional [FEDER] $]^{6}$ y

2 Reglamento (EU, Euratom) 2020/2093 del Consejo de 17 de diciembre de 2020 por el que se establece el marco financiero plurianual para el período 2021-2027.

3 Decisión (UE, Euratom) 2020/2053 del Consejo de 14 de diciembre de 2020 sobre el sistema de recursos propios de la Unión Europea y por el que se deroga la Decisión 2014/335/UE, Euratom.

4 Reglamento (UE) 2020/2094 del Consejo de 14 de diciembre de 2020 por el que se establece un Instrumento de Recuperación de la Unión Europea para apoyar la recuperación tras la crisis de la COVID-19.

5 Reglamento (UE) 2021/1057 del Parlamento Europeo y del Consejo de 24 de junio de 2021 por el que se establece el Fondo Social Europeo Plus (FSE+) y por el que se deroga el Reglamento (UE) n. ${ }^{0}$ 1296/2013.

6 Reglamento (UE) 2021/1058 del Parlamento Europeo y del Consejo de 24 de junio de 2021 relativo al Fondo Europeo de Desarrollo Regional y al Fondo de Cohesión. 
REALA. Nueva Época - N.o 16, octubre 2021 - ISSN: 1989-8975 - DOI: https://doi.org/10.24965/reala.i16.10994 - [Págs. 33-52]

Aplicación del régimen administrativo especial de los fondos Next Generation EU a las entidades locales

Francisco Velasco Caballero

el Fondo Europeo Agrícola para el Desarrollo Rural [FEADER]). Algo similar ocurre con varios programas sectoriales preexistentes y también financiados por la Unión, como los programas Horizonte Europa (para investigación), InvestEU (para inversiones estratégicas) y RescEU, para infraestructuras de emergencia (Calvo, 2020, p. 451; Marco, 2021, p. 366). Además, el Instrumento de Recuperación de la Unión Europea (IRUE) incluye nuevos fondos estructurales específicos para la recuperación post-Covid (además del MRR) que no se financian mediante el presupuesto ordinario, sino mediante la emisión de deuda prevista en el Instrumento de Recuperación Europeo: el REACT-EU 7 , con clara orientación hacia la salud pública y de ejecución territorizalizada (Villasalero, 2021, p. 223); y el Fondo de Transición Justa ${ }^{8}$, con enfoque ambiental (Pazos, 2021, p. 54).

3. En su traslado a los Estados miembros, la estrategia europea de recuperación no se limita a aportar cuantiosos recursos económicos a los Estados, en forma de subvenciones y de créditos. Los objetivos europeos de recuperación, que en buena medida son una aceleración o reimpulso de otras estrategias políticas previas (como la Agenda Digital $2030^{9}$, o el Pacto Verde Europeo ${ }^{10}$ ) no se reducen a la gestión de los nuevos fondos. Buscan la alineación general de los Estados miembros con los ejes de recuperación y transformación económica acordados por la Unión Europea (Sánchez-Barrueco, 2021, p. 587). Todos los niveles de gobierno en cada Estado, y en todos los ámbitos de la actuación pública, son llamados alinearse con los objetivos de recuperación de la Unión. Tanto con los nuevos recursos financieros europeos como con los recursos públicos propios, de cada Estado. Así se explica que incluso antes de que el Consejo aprobarse el Plan español de Recuperación, Transformación y Resiliencia (el 13 de julio de 2021), la Ley 11/2020, de 30 de diciembre, de Presupuestos Generales del Estado para el año 2021 ya anticipara autorizaciones de gasto alineadas con los objetivos y preferencias del Reglamento 2021/241 (MRR) (Ortega, 2021, pp. 40-55).

4. En su expresión externa, la alineación de los Estados con los objetivos europeos de recuperación se observa incluso en las denominaciones de los distintos instrumentos político-jurídicos. El Plan Europeo de Recuperación y Resiliencia tiene su correspondencia en el Plan (español) de Recuperación, Transformación y Resiliencia ("España puede"), y en planes de otras entidades territoriales españolas, como el Plan de Recuperación, Transformación y Resiliencia del Ayuntamiento de Madrid. La estrecha alineación de la estrategia europea y las actuaciones nacionales es posible, en gran medida, porque los objetivos europeos de recuperación no son nuevos. Son una versión actualizada e intensificada de políticas europeas preexistentes, en mayor o menor medida ya previamente proyectadas sobre las actuaciones estatales. Una buena parte de los proyectos innovadores que se incluyen en los nuevos planes domésticos (nacionales, autonómicos y locales) son, en realidad, proyectos previos: ya preparados, aprobados e incluso en ejecución. Esto no es una desviación aplicativa de la estrategia Next Generation EU, sino el buscado reforzamiento -mediante fuentes financieras extraordinarias- de aquellas actuaciones públicas ya en marcha que más directamente entroncan con los objetivos europeos de recuperación.

5. La alineación global de los Estados con los objetivos de recuperación de la Unión no sólo es una estrategia política, sino también Derecho de la Unión. La juridificación de la estrategia europea de recuperación (sobre todo a través del Reglamento 2021/241, que regula el MRR) tiene implicaciones importantes en el ámbito interno. De un lado, por la necesaria interpretación del Derecho nacional conforme al Derecho europeo (Alonso, 2012, p. 292; Arzoz, 2016, p. 17); y de otro lado, porque allí donde las normas nacionales impidieran o dificultaran por sí los objetivos normativos europeos, las autoridades nacionales habrían de dar primacía precisamente a las normas europeas (e inaplicar las nacionales). Ciertamente, la propia concisión de los reglamentos europeos para la recuperación aleja el riesgo de antinomia, y por tanto de desplazamiento aplicativo de las normas nacionales. Mayor trascendencia puede tener la interpretación y aplicación del Derecho interno conforme a los objetivos normativos europeos de la recuperación. De manera que, en la duda de cómo interpretar las normas nacionales (de contratación, subvencionales, presupuestarias, proce-

\footnotetext{
7 Reglamento (UE) 2020/2221 del Parlamento Europeo y del Consejo de 23 de diciembre de 2020 por el que se modifica el Reglamento (UE) núm 1303/2013 en lo que respecta a los recursos adicionales y las disposiciones de ejecución a fin de prestar asistencia para favorecer la reparación de la crisis en el contexto de la pandemia de COVID-19 y sus consecuencias sociales y para preparar una recuperación verde, digital y resiliente de la economía (REACT UE).

8 Reglamento (UE) 2021/1056 del Parlamento Europeo y del Consejo de 24 de junio de 2021 por el que se establece el Fondo de Transición Justa.

9 Comunicación de la Comisión al Parlamento Europeo, al Consejo, al Comité Económico y Social Europeo y al Comité de las Regiones (COM/2021/118 final).

10 Comunicación de la Comisión al Parlamento Europeo, al Consejo Europeo, al Consejo, al Comité Económico y Social y al Comité de las Regiones (COM/2019/640 final).
} 
REALA. Nueva Época - N.o 16, octubre 2021 - ISSN: 1989-8975 - DOI: https://doi.org/10.24965/reala.i16.10994 - [Págs. 33-52]

Aplicación del régimen administrativo especial de los fondos Next Generation EU a las entidades locales

Francisco Velasco Caballero

dimentales, competenciales) es necesario optar por aquella posibilidad aplicativa que facilite el pleno cumplimiento de los fines de recuperación que expresa el Derecho de la Unión. Este principio de interpretación del Derecho interno conforme al Derecho europeo puede favorecer la aplicación supletoria -por parte de las comunidades autónomas y de las entidades locales- de normas especiales dictadas por el Estado para la gestión (por la Administración del Estado) de los fondos europeos NGEU. Tal es el caso del Real Decreto-ley 36/2020, de 30 de diciembre, por el que se aprueban medidas urgentes para la modernización de la Administración Pública y para la ejecución del Plan de Recuperación, Transformación y Resiliencia (RDL-RTR), al que luego se prestará una atención detallada (infra § 45).

6. Al ejecutar cada plan de recuperación interno conforme al Reglamento 2021/241 hay que tener en cuenta que, a diferencia de otros previos fondos estructurales europeos, en este caso la financiación está estrechamente ligada a los resultados (Calvo, 2020, p. 453; Martínez Fernández, 2021, p. 2). Esto es, a los hitos (intermedios) y los objetivos (finales) propuestos por cada Estado en su propio Plan de Recuperación (aprobado por el Consejo mediante decisión ejecutiva). Estos hitos y objetivos, de cuyo efectivo cumplimiento depende el reembolso pautado de los gastos, necesariamente guían la actuación interna de los Estados. A eso se refiere el considerando 18 del Reglamento 2021/241 cuando dice que «(...) los métodos de ejecución que se establezcan conforme a este Reglamento deben elegirse con arreglo a su capacidad para cumplir los objetivos específicos de las acciones y para lograr resultados...». Esta adecuación de los «métodos de ejecución» internos incluye, a mi juicio, la interpretación de las propias normas administrativas nacionales de tal forma que permitan cumplir con los fines del MRR: la recuperación innovadora en los términos especificados por cada plan (nacional) de recuperación aprobado por el Consejo de la Unión Europea. Hay que tener en cuenta que, a diferencia de otros fondos europeos preexistentes, donde la Unión Europea no se centra en los resultados sino en la realidad y corrección de los costes reembolsables a los Estados (Pazos, 2021, p. 58), en el caso del MRR el Reglamento 2021/241 dirige su regulación hacia la consecución de los hitos y objetivos contenidos en el plan de recuperación de cada país. Esta neta orientación del MRR hacia los resultados (más que hacia la realidad de los costes reembolsables) lleva implícita la obligación de cada Estado de adecuar sus formas de actuación administrativa a fin de hacer realizables los hitos y objetivos aprobados por el Consejo en la decisión ejecutiva referida a cada país.

\section{EJECUCIÓN INTERNA DE LOS FONDOS EUROPEOS}

7. El cumplimiento de los hitos y objetivos del Plan de Recuperación, Transformación y Resiliencia de España (PRTR), así como de los correspondientes planes autonómicos y locales alineados con el plan estatal, requiere de una vasta actividad administrativa en un lapso muy limitado. España puede comprometer gasto financiable con trasferencias del MRR sólo entre 2021 y 2023. La ejecución de ese gasto ha de producirse antes del 31 de diciembre de 2026 (art. 24.1 del Reglamento 2021/240). La experiencia acumulada sobre la ejecución de fondos europeos muestra que las distintas Administraciones españolas no están en condiciones idóneas para gestionar tal volumen de recursos económicos. Así, tomando como referencia el Marco Financiero Plurianual 2014-2020, el Estado español en su conjunto dejó de gestionar 56.000 millones de euros (Calvo, 2020, p. 462). Es cierto que ese déficit de gestión no se explica sólo por posibles incapacidades administrativas, sino también por las obligaciones de co-financiación propias de los fondos estructurales europeos (matching grants). Con todo, el déficit en la absorción de fondos europeos disponibles entre 2014-2020 es un indicador de posibles dificultades en la gestión de los nuevos fondos (esta vez sin obligación de cofinanciación) del MRR.

\subsection{Agilización y simplificación administrativa estatal y autonómica}

8. La magnitud de la gestión económico-administrativa de los fondos europeos para la recuperación (en especial del MRR) ha justificado una reforma múltiple de la gestión administrativa, por medio del Real Decreto-ley 36/2020, de 30 de diciembre, por el que se aprueban medidas urgentes para la modernización de la Administración Pública y para la ejecución del Plan de Recuperación, Transformación y Resiliencia (RDL-RTR). El contenido del Real Decreto-Ley es muy diverso. Hay reglas de organización interna, de empleo público, de contratación, de subvenciones, presupuestarias y de gasto público, sobre convenios e incluso sobre evaluación ambiental de obras. Aunque algunas de las nuevas reglas son relevantes, no todas requerían una regulación con valor de ley. En buena medida, el RDL-PRTR no abre nuevas posibilidades o 
REALA. Nueva Época - N.o 16, octubre 2021 - ISSN: 1989-8975 - DOI: https://doi.org/10.24965/reala.i16.10994 - [Págs. 33-52]

Aplicación del régimen administrativo especial de los fondos Next Generation EU a las entidades locales

Francisco Velasco Caballero

formas de actuación, sino que impulsa o impone ciertas opciones organizativas o procedimentales ya posibles, conforme a las leyes administrativas vigentes. En estos casos, el RDL-PRTR actúa más como una instrucción u orden de servicio a la que se ha dado forma y valor de ley. Así, por ejemplo, el mandato de priorización para la digitalización de los procedimientos contractuales referidos a los fondos europeos (art. 36.2 RDL-PRTR) es una determinación que bien podía adoptar la forma de instrucción interna, o de orden de servicio. En estos casos, el verdadero efecto normativo del RDL-PRTR consiste en reducir la discrecionalidad organizativa de los órganos administrativos.

9. El Real Decreto-Ley 36/2020 afecta de forma también diversificada a las leyes administrativas vigentes. Unas veces, el Real Decreto-Ley modifica -esto es, deroga parcialmente- leyes administrativas previas, tanto generales (como la Ley de Contratos del Sector Público, la General de Subvenciones y la Ley de Régimen Jurídico del Sector Público) como sectoriales (es el caso de la Ley 21/2013, de 9 de diciembre, de Evaluación Ambiental). Otras veces el RDL-PRTR regula materias o cuestiones ya reguladas en previas leyes administrativas, pero no las deroga, sino que dispone un régimen administrativo especial para la gestión administrativa de los fondos europeos, pero sin modificar el texto de las leyes generales. Finalmente, el mismo Real Decreto-Ley 36/2020 también crea nuevos instrumentos de gestión, no regulados hasta ahora en previas leyes administrativas: es el caso de los llamados PERTE (Proyectos Estratégicos de Recuperación y Transformación Económica). Luego veremos la relevancia de esta tipología de normas del RDL-PRTR para su aplicación en las comunidades autónomas y las entidades locales (infra § 45).

10. El Real Decreto-Ley 36/2020 no predetermina la forma de gestión de los fondos europeos. Esto es, todas las formas de actuación administrativa actualmente vigentes (contratos, subvenciones, convenios, consorcios, sociedades mercantiles, encomiendas de gestión, etc.) pueden ser cauce idóneo para la gestión de los fondos europeos. Incluso el novedoso PERTE, al que se hará referencia específica más abajo (infra § 20), no es en puridad una nueva forma de actuación administrativa, sino un procedimiento para la selección de actuaciones y sujetos financiables. Tales sujetos actuarán mediante las formas jurídicas típicas de la Administración: subvenciones, contratos, convenios, encomiendas. Dado que el Real Decreto-Ley 36/2020 no crea nuevas formas de gestión, su verdadero objeto es sustituir selectivamente algunas reglas organizativas y procedimentales específicas que rigen las formas ordinarias de gestión. Todas estas reglas nuevas están dirigidas a simplificar y agilizar la gestión administrativa, bien con carácter general, bien en relación con los fondos europeos Next Generation EU.

11. En gran medida, la agilización o simplificación administrativa consiste en la reducción de los plazos de tramitación de expedientes, o en la supresión de algunos trámites procedimentales. En general, no hay en el Real Decreto-Ley 36/2020 una redefinición profunda de los procedimientos administrativos, sino una más simple y modesta adaptación de trámites (Crítico: Bustos, 2021, pp. 241 y 264). La reducción de plazos en la tramitación, aunque sin duda que puede agilizar la gestión de los fondos y proyectos, es una opción cuestionable y objetable. Primero, porque el cumplimiento de los plazos procedimentales, salvo en aquellos casos en los que rige el silencio administrativo positivo conforme al art. 24.1 de la Ley 39/2015, de 1 de octubre, del Procedimiento Administrativo Común de las Administraciones Públicas (LPAC), lo que no ocurre en ninguna de las posibles formas de ejecución del MRR, es difícilmente coercible. En segundo lugar, una mayor concentración de recursos humanos y técnicos en la gestión del PRTR lógicamente supone desatender otros procedimientos administrativos que también han de tramitarse con celeridad (art. 71.1 LPAC) y en plazo (arts. 29 y 73 LPAC). Es cierto que las novedades de empleo público que incorpora el Real Decreto-Ley 36/2020 (como la provisión de puestos de trabajo en unidades temporales [arts. 24.4, 28 y 29] y en unidades estructurales [art. 30], o como la asignación de funciones a tiempo parcial [art. 31]) pueden coadyuvar a una gestión ágil del PRTR, pero también es cierto que alcance real de estas medidas de empleo es más bien limitado.

12. Otras medidas de agilización y simplificación consisten en la supresión de trámites. Dos son las cuestiones que plantean estas medidas. En primer lugar, si la supresión de un trámite resulta verdaderamente posible, seguidamente habría que plantearse su supresión general, no sólo para la gestión de los recursos vinculados al PRTR. En segundo lugar, si el trámite en cuestión no era verdaderamente superfluo surgen dudas sobre de qué forma alternativa se satisface ahora el interés público al que servía ese trámite. Así, si determinados trámites de intervención económica cumplían una función cualificada, su supresión en el RDL-PRTR tendría que venir compensada con alguna otra técnica de control menos gravosa. Por ejemplo, mediante un aumento de la transparencia (acceso universal) de los correspondientes expedientes de gasto.

13. Como luego se explicará con más detenimiento (infra § 27), el complejo RDL-PRTR presenta muy diversos ámbitos y niveles de aplicación. Tanto desde el punto de vista objetivo (se aplica diferenciadamente 
REALA. Nueva Época - N.o 16, octubre 2021 - ISSN: 1989-8975 - DOI: https://doi.org/10.24965/reala.i16.10994 - [Págs. 33-52]

Aplicación del régimen administrativo especial de los fondos Next Generation EU a las entidades locales

a la ejecución de los distintos fondos europeos) como desde la perspectiva subjetiva: se aplica diferenciadamente a las distintas Administraciones públicas. Una buena parte de su regulación se aplica a todas las Administraciones públicas; pero otra parte se aplica sólo a la Administración General del Estado (infra § 32). De ahí que abiertamente se haya planteado que las comunidades autónomas y las entidades locales aprueben sus propias normas de agilización administrativa para la gestión de los fondos europeos (Bustos, 2021, p. 251). En la actualidad, son ya muchas las comunidades autónomas que, previendo la ejecución territorializada de una parte de los fondos europeos, han aprobado también sus propias normas de agilización y simplificación administrativa (infra § 15): bien para complementar la regulación común del Estado (básica o plena), bien para aquellas cuestiones que, aun estando reguladas en el RDL-PRTR, tal regulación sólo es aplicable a la Administración estatal. Más compleja es la aprobación de normas locales de agilización administrativa, en la medida en que las entidades locales carecen de potestad legislativa y una gran parte de la actuación administrativa local se encuentra regulada en leyes, tanto generales como sectoriales y tanto estatales como autonómicas. Sólo mediante medidas de organización interna, por estar amparadas directamente por el art. 4.1 a) LBRL, se pueden replicar en al ámbito local algunas de las medidas contenidas en el Real Decreto-Ley 36/2020 (Martínez Fernández, 2021, p. 6). De ahí la relevancia de plantearse la posible aplicación supletoria, por parte de las entidades locales, de las demás reglas de agilización administrativa para la gestión de los fondos europeos (infra § 45).

14. Las nuevas normas autonómicas, unas reglamentarias y otras con valor de ley, en buena medida reproducen los preceptos del RDL-PRTR que sólo son aplicables a la Administración estatal. Así, por ejemplo, la regulación de las «unidades administrativas provisionales» en el art. 24.2 y 3 RDL-PRTR tiene su correspondencia en el art. 7 del Decreto-Ley extremeño 3/2021, de 3 de marzo, de medidas urgentes para la modernización de la Administración Pública y para la ejecución del Plan de Recuperación, Transformación y Resiliencia. Aunque, junto a esta opción normativa reproductiva, las normas autonómicas también incluyen algunas reformas estructurales de su propio sector público (por tanto, no limitadas a la gestión de los fondos europeos) y algunas variaciones respecto del RDL-PRTR. Por ejemplo, la provisión de puestos de trabajo en las «unidades administrativas provisionales» se ha de hacer preferentemente (en la Administración estatal) mediante la redistribución y la reasignación de efectivos (arts. 24. 4 y 30 RDL-PRTR) mientras que en Extremadura se ha de hacer primeramente mediante atribución temporal de funciones y comisiones de servicios (art. 10.1 del Decreto-Ley extremeño 3/2021, de 3 de marzo).

15. Esta doble regulación administrativa, estatal y autonómica, sólo en parte es aplicable a las entidades locales que gestionen fondos europeos. Excepto las normas básicas o plenas del RDL-PRTR, que en principio se dirigen a todas las Administraciones públicas, las demás reglas de agilización o simplificación administrativas (tanto estatales como autonómicas) no son directamente aplicables a las entidades locales. Las leyes autonómicas que han replicado el RDL-PRTR por lo general han circunscrito su ámbito de aplicación a la propia Administración autonómica, excluyendo a las entidades locales ${ }^{11}$. Como excepción, algunos preceptos autonómicos sobre contratación administrativa (en desarrollo de las modificaciones que el RDL-PRTR introduce en la LCSP) se aplican también a la contratación local ${ }^{12}$. Posiblemente, la frecuente exclusión aplicativa de las nuevas normas administrativas respecto de las entidades locales resulta del prejuicio inicial de que las entidades locales no son Administraciones principales para la gestión de los fondos europeos para la ejecución del PRTR (Crítico: Prieto, 2021, p. 508). Si es así, este prejuicio está siendo cuestionado por la existencia de diversos planes, iniciativas, estrategias y «manifestaciones de interés» formuladas por grandes ayuntamientos y por diputaciones provinciales. A la vista de esta realidad, y de algunos

11 Art. 2.1 del Decreto-ley andaluz 3/2021, de 16 de febrero, por el que se adoptan medidas de agilización administrativa y racionalización de los recursos para el impulso a la recuperación y resiliencia en el ámbito de la Comunidad Autónoma de Andalucía; art. 2 del Decreto-Ley extremeño 3/2021, de 3 de marzo, de medidas urgentes para la modernización de la Administración Pública y para la ejecución del Plan de Recuperación, Transformación y Resiliencia; art. 1 del Decreto-ley valenciano 6/2021, de 1 de abril, del Consell, de medidas urgentes en materia económico-administrativa para la ejecución de actuaciones financiadas por instrumentos europeos para apoyar la recuperación de la crisis consecuencia de la Covid-19; art. 2 de la Ley castellano-manchega 4/2021, de 25 de junio, de Medidas Urgentes de Agilización y Simplificación de Procedimientos para la Gestión y Ejecución de los Fondos Europeos de Recuperación.

12 Arts. 2.3 y 12.3 del Decreto-Ley catalán 5/2021, de 2 de febrero, por el que se aprueban medidas urgentes para la implementación y gestión de los fondos procedentes del Mecanismo de Recuperación y Resiliencia y del Fondo REACT-EU para la Administración de la Generalidad de Cataluña y su sector público; art. 2.2 del. Decreto-ley canario 4/2021, de 31 de marzo, de medidas urgentes para la agilización administrativa y la planificación, gestión y control de los Fondos procedentes del Instrumento Europeo de Recuperación denominado "Next Generation EU”, en el ámbito de la Comunidad Autónoma de Canarias y por el que se establecen medidas tributarias en el Impuesto General Indirecto Canario para la lucha contra la COVID-19. 
REALA. Nueva Época - N.o 16, octubre 2021 - ISSN: 1989-8975 - DOI: https://doi.org/10.24965/reala.i16.10994 - [Págs. 33-52]

Aplicación del régimen administrativo especial de los fondos Next Generation EU a las entidades locales

Francisco Velasco Caballero

indicios políticos sobre la futura y efectiva participación de las entidades locales en la gestión de los fondos europeos, surge la paradoja de que la actuación administrativa del Estado y de las comunidades autónomas se va a dar en condiciones de agilidad y simplificación (conforme a las nuevas leyes y decretos-leyes especiales para los fondos europeos) mientras que las entidades locales, que no pueden aprobar ordenanzas o reglamentos especiales respecto de las leyes generales del Estado o de las comunidades autónomas, se van a regir por normas que -para el propio Estado y las propias comunidades autónomas- no son ni ágiles ni sencillas. Se plantea entonces, ante esta paradoja, en qué medida las leyes especiales del Estado y las comunidades autónomas pueden ser aplicables, de forma supletoria, a las entidades locales, cuando ejecuten proyectos financiados con fondos europeos (infra § 45).

\subsection{Participación local en la gestión del PRTR}

16. Desde el principio, el MRR europeo y el PRTR español responden a estrategias centralizadas, tanto en su elaboración ${ }^{13}$ como en su ejecución (Bustos, 2021, p. 255; Colás, 2021, p. 43). Esa centralización original se puede explicar por la urgencia en activar el instrumento NGEU y por la opción explícita de concentración de la nueva financiación europea en grandes proyectos de transformación económica y social (a diferencia de otros fondos más reticulares, como los fondos estructurales y de cohesión destinados al equilibrio territorial y al sostenimiento de rentas).

17. La estrategia de centralización estatal, a la hora de ejecutar el PRTR, no es contraria al Derecho Europeo. El Derecho de la Unión Europea no predetermina el nivel de gobierno con el que ejecutar el MRR, al que sirve el Plan Nacional de Recuperación, Transformación y Resiliencia. A diferencia de los fondos estructurales europeos, que sí exigen la participación y asociación de las entidades territoriales y de la sociedad civil (principio de asociación) ${ }^{14}$, esa exigencia no se encuentra ni en el Instrumento de Recuperación de la Unión Europea (IRUE) ni específicamente en el MRR. Sí se puede sostener que esa asociación o ejecución multinivel es necesaria cuando la financiación extraordinaria europea prevista en el IRUE se canalice a través de los fondos estructurales (como el FEDER o el FEADER) que sí exigen una ejecución multinivel.

18. En todo caso, si bien conforme al Derecho europeo la gestión del MRR puede ser centralizada, también es posible una gestión sustancialmente territorializada o descentralizada siguiendo el patrón de los fondos estructurales (Pazos, 2021, p. 72). Esto es, a través de las comunidades autónomas y de las entidades locales. Se puede considerar inicialmente, incluso, que conforme a la jurisprudencia financiera del Tribunal Constitucional ${ }^{15}$, la territorialización de los recursos (a favor de las comunidades autónomas) será preceptiva -aunque no necesariamente plena- para la financiación de actuaciones enclavadas en materias competenciales autonómicas (como el desarrollo normativo y la ejecución de las bases estatales sobre energía; o como el desarrollo normativo y la ejecución ambiental). De hecho, expresamente el art. 44 RDL-PRTR prevé la ejecución autonómica del PRTR (aunque no precisa su alcance). Algo similar, aunque con mucho menos alcance, se puede predicar de las entidades locales. En este caso, la garantía constitucional de autonomía local (art. $137 \mathrm{CE}$ ) impide que, al menos en los ámbitos competenciales atribuidos como propios por las leyes generales o sectoriales, se ejecuten proyectos de interés local sin una participación cualificada de los propios gobiernos locales (Velasco, 2009, p. 49; Domínguez, 2021, p. 426 § 7). Es cierto que -hasta hoy y en términos generales- la jurisprudencia constitucional ha sido poco tuitiva de la autonomía local en relación con actuaciones estatales o autonómicas con claro interés y escala locales ${ }^{16}$. Pero incluso bajo esta jurisprudencia debe ser recognoscible un mínimo de participación local en la definición y la ejecución de las actuaciones definidas en el PRTR y financiadas con el MRR (o con otros fondos europeos instrumen-

13 Para el MRR: Resolución del Comité Económico y Social Europeo sobre la Participación de la sociedad civil organizada en los planes nacionales de recuperación y resiliencia -¿Qué funciona y qué no funciona?- (sobre la base de las consultas realizadas en los 27 Estados miembros), 2021/C 155/01, de 30 de abril de 2021.

14 Art. 8.1 del Reglamento (UE) 2021/1060 del Parlamento Europeo y del Consejo de 24 de junio de 2021 por el que se establecen las disposiciones comunes relativas al Fondo Europeo de Desarrollo Regional, al Fondo Social Europeo Plus, al Fondo de Cohesión, al Fondo de Transición Justa y al Fondo Europeo Marítimo, de Pesca y de Acuicultura, así como las normas financieras para dichos Fondos y para el Fondo de Asilo, Migración e Integración, el Fondo de Seguridad Interior y el Instrumento de Apoyo Financiero a la Gestión de Fronteras y la Política de Visados.

15 Desde la STC 13/1992, FJ 8, hasta nuestros días (STC 138/2021, FJ 3), aunque con alguna desviación aplicativa (como la que expresa la STC 179/2016, FJ 2).

16 Así, en relación con la financiación extraordinaria para abastecimiento y saneamiento municipal de agua en Andalucía: STC 136/2016, FJ 5. 
REALA. Nueva Época - N.o 16, octubre 2021 - ISSN: 1989-8975 - DOI: https://doi.org/10.24965/reala.i16.10994 - [Págs. 33-52]

Aplicación del régimen administrativo especial de los fondos Next Generation EU a las entidades locales

Francisco Velasco Caballero

talizados por el IRUE) que directamente afecten a intereses predominantemente locales. Sin duda que las exigencias de efectividad en la gestión del MRR puede excluir la participación directa de los pequeños municipios en la gestión de los fondos europeos (Pazos, 2021, p. 73), pero no permite excluir la participación de los grandes municipios y de las entidades locales de segundo nivel (provincias, municipios, islas, territorios históricos, comarcas).

19. Para la participación autonómica en la gestión del MRR pueden ser instrumentos fundamentales -entre otros- las subvenciones o transferencias estatales y autonómicas, los convenios interadministrativos o incluso los consorcios con participación autonómica. También, la participación local, tanto en proyectos estatales como en proyectos autonómicos con financiación del MRR, se puede articular a través de subvenciones, convenios (Pazos, 2021, p. 70), consorcios y otras formas de cooperación institucionalizada $^{17}$. La cuestión es, entonces, cuál será el régimen jurídico de esas actuaciones ejecutivas locales financiadas con el MRR ( $u$ otros fondos europeos comprendidos en el IRUE). En especial, si todos estos actos, procedimientos y actuaciones locales se rigen, en alguna medida, por las reglas de agilización contenidas en el Real Decreto-Ley 36/2020 y en las leyes y decretos-leyes autonómicas para la gestión de los fondos europeos NGEU.

\subsection{Participación local en los proyectos estratégicos para la recuperación y transformación económica}

20. El art. 8 RDL-PRTR incluye un instrumento novedoso de gestión de los fondos europeos, el llamado PERTE (Proyecto Estratégico de Recuperación y Transformación Económica). En puridad, el Real Decreto-Ley 36/2020 no regula el PERTE como una forma de actuación administrativa, sino como una estructura o espacio administrativo en cuyo seno cooperan los diversos ministerios concernidos entre sí y con otros sujetos públicos y privados externos a la Administración General del Estado. Hay que plantearse ahora en qué medida las entidades locales participan en ese «espacio administrativo» para la colaboración público-privada. Aunque el propio Real Decreto-Ley incluye algunas normas sobre el PERTE, en gran medida remite su configuración acabada a dos tipos de actos jurídicos posteriores: el acuerdo de creación de cada PERTE, por el Consejo de Ministros (art. 8.2 RDL-PRTR); y la regulación reglamentaria del registro de entidades interesadas en los PERTE. El acuerdo de creación del PERTE no tiene naturaleza normativa, y por tanto no define por sí ninguna situación jurídica (art. 24. 1 de la Ley 50/1997, del Gobierno). En cambio, la regulación reglamentaria del registro de entidades interesadas sí es propiamente normativa, y puede definir la situación jurídica de esas entidades. Dos son las regulaciones reglamentarias previstas para el registro: una regulación general, dictada por la Ministra de Hacienda para el conjunto del registro; y una específica para cada PERTE, que ha de aprobarse por la Ministra sectorialmente competente (art. 9.4 RDL-PRTR).

21. Según las previsiones del PRTR, los PERTE serán reducidos en número (actualmente los ministerios trabajan en ocho proyectos) y serán de muy elevada cuantía cada uno, a fin de concentrar muchos recursos económicos en sectores económicos muy específicos e innovadores. Esta alta concentración de recursos en pocos PERTE debe evitar también una gestión administrativa muy capilar, en muchos pequeños proyectos. En principio, esta definición de los PERTE no tiene como destinatarios preferentes a los gobiernos locales. Aunque esa participación también es posible (Prieto, 2021, p. 531), en la medida en que, siguiendo el patrón normativo del art. 8 RDL-PRTR, los PERTE se regulen como estructuras cooperativas que agrupan a muy diversos sujetos, públicos y privados (Colás, 2021, p. 48).

22. Según se ha dicho ya, la realidad jurídica de los PERTE queda remitida a posteriores decisiones gubernativas. Pues bien, el pasado 13 de julio el Consejo de Ministros aprobó el primer PERTE, el relativo al vehículo eléctrico y conectado (VEC). Está en fase muy avanzada de elaboración de un segundo PERTE para el sector agroalimentario. En relación con el PERTE VEC, integran el acuerdo del Consejo de Ministros tanto la justificación del acuerdo como una Memoria (Anexo I) y una estructura de «gobernanza» (Anexo II). Veamos ahora en qué medida los dos anexos abren el PERTE VEC a los gobiernos locales. En la memoria del PERTE VEC se definen dos ámbitos de actuación: el «impulso de los proyectos transformadores en la cadena de valor del VEC»; y las «medidas facilitadoras que pueden coadyuvar tanto a la creación de una

17 Es el caso de la concertación autonómico-local regulada en la Disposición final 1. a de la Ley extremeña 3/2021, de 3 de marzo, de medidas urgentes para la modernización de la Administración Pública y para la ejecución del Plan de Recuperación, Transformación y Resiliencia, que modifica el art. 46 de la Ley extremeña 3/2019, de 22 de enero, de Garantía de la Autonomía Municipal de Extremadura. 
REALA. Nueva Época - N.o 16, octubre 2021 - ISSN: 1989-8975 - DOI: https://doi.org/10.24965/reala.i16.10994 - [Págs. 33-52]

Aplicación del régimen administrativo especial de los fondos Next Generation EU a las entidades locales

nueva movilidad como al desarrollo del vehículo eléctrico» ${ }^{18}$. En principio, se puede excluir que las entidades locales puedan participar en la producción de los vehículos eléctricos y conectados. Pero también parece claro que las infraestructuras de movilidad sostenible (para el vehículo eléctrico y conectado) en buena medida requieren de la colaboración local. Ello no obstante, como en seguida se verá, los gobiernos locales no están presentes en el Acuerdo que declara el PERTE VEC. Varios son los aspectos destacables del Acuerdo, desde la perspectiva local.

23. En primer lugar, como ya había anunciado el art. 8.2 del Real Decreto-Ley 36/2020, el acuerdo del Consejo de Ministros no contiene propiamente el régimen jurídico del PERTE. El acuerdo gubernativo define con detalle el objetivo político-económico del PERTE VEC (Anexo I), pero no lo regula. Únicamente, el acuerdo gubernativo crea dos órganos colegiados para la "gobernanza» del PERTE VEC: un órgano colegiado interministerial, el "Grupo de Trabajo Interministerial del PERTE VEC", presidido por la Ministra de Industria, Comercio y Turismo (Sección 1, apartado 1.․); y la Alianza para el Vehículo Eléctrico y Conectado, integrada por cargos públicos ministeriales y representantes del sector empresarial automovilístico ya presentes en la Mesa de la Automoción (Sección 2, apartado 4. ${ }^{\circ}$ ). Formalmente, tanto el Grupo de Trabajo como la Alianza son órganos administrativos colegiados, y por tanto a ambos se les aplicarán las leyes administrativas, en especial, los arts. 15 a 24 LRJSP. Ambos son órganos colegiados interministeriales no decisorios (art. 22.3 LRJSP). Desde la perspectiva propiamente local, en el acuerdo de creación claramente se observa el carácter netamente estatal y la orientación público-privada del PERTE. En primer lugar, la presencia de los gobiernos locales en el grupo de trabajo es nula, pese a que el art. 21.2 LRJSP permite la inclusión de representantes de otras Administraciones públicas en los órganos colegiados interministeriales. En segundo lugar, los representantes (privados) del sector empresarial del automóvil se integran, como tales representantes, en un órgano administrativo (la Alianza), opción permitida por el art. 21.3 LRJSP. Según se ve, la estructura de «gobernanza» del PERTE está más abierta al sector privado (a través de la Alianza) que a las demás entidades públicas.

24. EI PERTE VEC no cuenta -por ahora- con el registro de entidades interesadas que anunciaban el art. 9 y la DA 1. ${ }^{a}$ RDL-PRTR. Es cierto que el Real Decreto-Ley no precisa con claridad la función de este registro, salvo su localización en el Ministerio de Hacienda. Menciona de forma imprecisa la posibilidad de «ayudas» a las entidades interesadas registradas (art. 11.1 RDL-PRTR), pero nada más dice de tales ayudas (Montes, 2021, p. 534). En realidad, la regulación sustantiva del registro en su conjunto se remite al Ministerio de Hacienda, y la regulación de cada sección (para cada concreto PERTE) se remite al Ministerio sectorialmente competente (art. 9.4 RDL-PRTR). Con todo, la escueta regulación del Real Decreto-Ley sugiere que la ejecución de los PERTE está abierta a todos los sujetos públicos y privados interesados. Es una forma de incorporar a la ejecución del PERTE a entidades -públicas y privadas- que no habían participado previamente en las «manifestaciones de interés» que han dado lugar al Plan de Recuperación y al acuerdo del PERTE VEC. El hecho de que este PERTE se haya creado sin el registro de entidades interesadas sugiere que su ejecución se va a canalizar más a través de las empresas que ya forman parte del sector (y que como tales están representadas en la Alianza). Desde la perspectiva local, dado que los ayuntamientos y diputaciones provinciales no forman parte de la estructura organizativa (gobernanza) del PERTE VEC, y que la participación como entidades interesadas es por ahora una incógnita (por falta de creación del registro correspondiente), hay que considerar que la posible actuación local en los PERTE queda relegada estrictamente a la fase de ejecución indirecta.

25. El acuerdo del Consejo de Ministros que aprueba el PERTE VEC, de 13 de julio de 2021, define unos objetivos y una estructura organizativa para su consecución. Pero no establece concretas formas de actuación administrativa. Esto es conforme con el propio art. 8 RDL-PRTR, que no configura el PERTE como una forma de actuación, sino como una estructura organizativa para la colaboración público-privada. El propio apartado 1 del acuerdo gubernativo encarga a varios ministerios que «desarrollen las medidas de apoyo descritas en la memoria del Acuerdo». En este sentido, conforme al art. 8.4 RDL-PRTR queda ahora abierta la posibilidad, que habrá de ir concretando el "grupo de trabajo», de que el PERTE se ejecute en cada ministerio a través de cualquiera de las formas de colaboración privada existentes en la actualidad (Gimeno, 2021, p. 95).

26. Aunque ni el PRTR ni el Real Decreto-Ley 36/2020 optan por concretas formas de ejecución administrativa, lo cierto es que el PERTE VEC sí se decanta decididamente por las ayudas económicas a las en-

18 Ministerio de Industria, Comercio y Turismo (2021, p. 54). Accesible en www.mincotur.gob.es. 
REALA. Nueva Época - N.o 16, octubre 2021 - ISSN: 1989-8975 - DOI: https://doi.org/10.24965/reala.i16.10994 - [Págs. 33-52]

Aplicación del régimen administrativo especial de los fondos Next Generation EU a las entidades locales

tidades participantes, otorgadas en procedimientos competitivos. Esas ayudas toman forma de subvención no reembolsable (directamente con cargo a los fondos del MRR) o de crédito reembolsable (con cargo al presupuesto general del Estado, alineado con los recursos del MRR) ${ }^{19}$. En este contexto de ayudas públicas, la presencia de los gobiernos locales es por completo secundaria, pese a su posible relevancia para las «medidas facilitadoras», ya mencionadas. En la memoria del PERTE VEC tan sólo se hace referencia al ámbito local en tres aspectos: incremento del 10 por 100 de las ayudas para la adquisición de vehículos eléctricos cuando los adquirentes residan en municipios de menos de 5.000 habitantes; obligatoriedad (como «medida facilitadora») de que los municipios de más de 50.000 habitantes cuenten antes de 2023 con «planes de movilidad urbana sostenible»; y previsión de ayuda financiera específica para el despliegue de la red $5 \mathrm{G}$ en las «zonas de ruralidad extrema». En principio, la clara secundariedad de las entidades locales en la memoria del PERTE VEC no impide que las entidades locales actúen como sujetos perceptores de ayudas conforme al régimen legal general de las subvenciones (Pastor, 2017, p. 299), siempre que se integren en una «agrupación» junto con empresas privadas y suscriban el acuerdo interno de cada agrupación. También es posible que entidades locales instrumentales (organismos públicos o sociedades locales) participen también como socio tecnológico o productivo en una agrupación para la ejecución del PERTE. Esta posibilidad no ofrece problemas para las subvenciones, que bien pueden ser percibidas por una entidad local instrumental, pero sí para los créditos, por las limitaciones propias de la Ley Orgánica 2/2012, de 27 de abril, de Estabilidad Presupuestaria y Sostenibilidad Financiera.

\section{APLICACIÓN A LAS ENTIDADES LOCALES DE LAS NORMAS ESPECIALES DE AGILIZACIÓN Y SIMPLIFICACIÓN ADMINISTRATIVA}

\subsection{Reglas administrativas estatales}

27. Ya se ha dicho antes (supra § 8) que las medidas de agilización administrativa contenidas en el Real Decreto-Ley 36/2020 son muy diversas. También son muy diferentes los ámbitos de aplicación de sus normas, tanto desde el punto de vista subjetivo (a qué Administraciones públicas se aplica cada norma de agilización) como temporal y objetivo (a qué tipo de actuaciones administrativas se aplican las reformas) ${ }^{20}$. En principio, el art. 2 del RDL 36/2020 utiliza sólo un criterio objetivo (el tipo de actividad administrativa) para definir el ámbito de aplicación del Real Decreto-Ley. Desde el punto de vista subjetivo, el art. 2.1 del propio Real Decreto-Ley lo declara aplicable a todas las entidades que integran el sector público (por tanto, conforme al art. 2.1 de la Ley 40/2015, de 1 de octubre, del Régimen Jurídico del Sector Público [LRJSP], es aplicable a las entidades locales y a sus entidades instrumentales). Ello no obstante, son muchas las concretas normas del RDL-PRTR que, por su propio contenido, explícita o implícitamente sólo son aplicables a la Administración General del Estado. Luego se volverá sobre esto (infra § 33). Primero vamos a abordar la vigencia temporal y objetiva del RDL 36/2020.

\subsection{Vigencia temporal}

28. En lo que hace a la vigencia temporal, el Real Decreto-Ley 36/2020 ofrece múltiples regulaciones. Una parte de sus reglas, aquellas que modifican de forma definitiva previas leyes administrativas, tienen vigencia indefinida. Esto es, ciertas reglas administrativas generales se aplicarán a partir de ahora y para todo tipo de supuestos (no sólo los vinculados a la ejecución del PRTR). Así ocurre con todas las normas que modifican previas leyes administrativas estatales. Es el caso del nuevo régimen de los informes vinculantes de

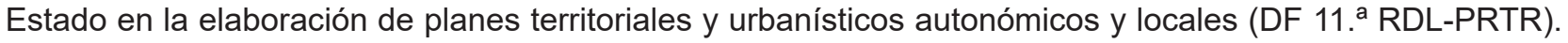
Otras normas de agilización procedimental rigen de forma sólo temporal, para la gestión de los fondos europeos. Así ocurre, por ejemplo, con la DA 2. ${ }^{a}$ RDL-PRTR, sobre retribuciones extraordinarias de empleados públicos que gestionen fondos europeos ligados al PRTR. De esta forma, una vez ejecutado el MRR (o los otros fondos también vinculados al programa Next Generation EU) estas reglas de agilización administrativa habrán perdido por completo su vigencia.

19 Ministerio de Industria, Comercio y Turismo (2021, pp. 62 y 83)

20 Crítico con esta compleja definición del ámbito de aplicación del Real Decreto-Ley: Dictamen del Consejo de Estado núm. 783/2020, de 21 de diciembre de 2020, p. 34. 
REALA. Nueva Época - N.o 16, octubre 2021 - ISSN: 1989-8975 - DOI: https://doi.org/10.24965/reala.i16.10994 - [Págs. 33-52]

Aplicación del régimen administrativo especial de los fondos Next Generation EU a las entidades locales

Francisco Velasco Caballero

\section{3. Ámbitos objetivos de aplicación}

29. Desde el punto de vista objetivo, el Real Decreto-Ley 36/2020 contiene varios criterios de aplicación complementarios. Una parte de las nuevas reglas, en especial aquellas que modifican leyes administrativas anteriores, se aplican de forma universal, no sólo a las actuaciones administrativas vinculadas a la ejecución de proyectos europeos. Esto es, se aplican a todas las actuaciones subsumibles en el correspondiente supuesto de hecho normativo de las leyes generales, ahora modificadas. Así ocurre, por ejemplo, en la DF 3. ${ }^{\text {a }} 3$ RDL-PRTR, que modifica algunos plazos básicos en la evaluación ambiental estratégica regulada en la Ley 21/2013, de 9 de diciembre, de Evaluación Ambiental. Esta nueva regulación de la evaluación ambiental se aplica a todos los procedimientos de esa clase (sea cual sea la Administración competente y su vinculación mayor o menor con un proyecto de ejecución del PRTR). En este caso, es claro que el criterio objetivo de aplicación de las nuevas normas procedimentales no es la gestión de fondos europeos, aunque obviamente también se aplique a ellos (e incluso haya sido la razón que ha impulsado la reforma legislativa general).

30. Conforme al art. 2. 2, 3 y 4 RDL-PRTR, otras normas del Real Decreto-Ley se aplican de forma más selectiva, sólo a actuaciones administrativas financiadas con los fondos europeos. Este criterio objetivo, aparentemente sencillo, se complica porque el propio art. 2 RDL-PRTR incluye varias distinciones (Villasalero, 2021, p. 6).

a) Así, algunas normas (las que regulan las estructuras de gestión del PRTP) se aplican a las actuaciones financiadas con alguno de los fondos europeos (aparte del MRR) que expresamente enumera el propio precepto (por tanto, no con cualquier fondo europeo). De esta manera, ciertas reglas de gestión del Real Decreto-Ley 36/2020 se aplican no sólo a las actuaciones de ejecución del MRR, sino también de otros fondos europeos alineados en la estrategia Next Generation EU. Esto puede ser relevante para una ejecución autonómica y local más ágil de fondos estructurales ya preexistentes (Pazos, 2021, p. 20). Se refiere el art. 2.2 RDL-PRTR, además de a los fondos del Instrumento de Recuperación de la Unión Europea, al Fondo Europeo de Desarrollo Regional (FEDER), al Fondo Social Europeo (FSE+), al Fondo Europeo Agrícola de Desarrollo Rural (FEADER) y al Fondo Europeo Marítimo y de Pesca. Otros fondos europeos (como el Fondo de Transición Justa, o el REACTEU) no están expresamente mencionados en el art. 2.2 RDL-PRTR, por lo que a priori se podría plantear la duda sobre si su gestión se rige también por el Real Decreto-Ley. Sobre ello hay que recordar que el art. 2.2 RDL-PRTR se refiere en sentido amplio a los fondos del Instrumento de Recuperación de la Unión Europea y no sólo al concreto Mecanismo de Recuperación y Resiliencia (MRR). Esto permite sostener que la referencia del art. 2.2 RDL-PRTR es no sólo al MRR, sino también a los otros nuevos fondos europeos (o preexistentes pero ahora instrumentalizados en el programa Next Generation EU) a los que se refiere el art. 2 del Reglamento (UE) 2020/2094.

b) Conforme al art. 2.3 RDL-PRTR, otra parte de sus normas -las referidas a las estructuras de gobernanza del Plan de Recuperación, Transformación y Resiliencia- se aplican únicamente a los fondos del Mecanismo Recuperación y Resiliencia (y no, por tanto, a las actuaciones financiables con otros fondos incluidos en el Instrumento Europeo de Recuperación).

31. En relación con las normas que rigen sólo para la gestión administrativa de fondos europeos, y sea más amplio o más estrecho su ámbito de aplicación (los fondos a los que afecta) lo cierto es que el criterio principal de aplicación del Real Decreto-Ley 36/2020 es objetivo, financiero y funcional. El ámbito de aplicación subjetivo (las Administraciones públicas que se rigen por las distintas normas del RDL-PRTR) bien puede considerarse como subalterno o de segundo grado, respecto del ámbito objetivo. Por eso, vista la opción normativa primaria del Reglamento UE 2021/241, que impone a los Estados una gestión eficiente del MRR, hay que considerar -como criterio de principio- la aplicación del Real Decreto-Ley 36/2020 allí donde haya gestión administrativa de los fondos europeos, precisamente porque las reglas de agilización del RDL-PRTR están dirigidas a una eficaz gestión del Instrumento de Recuperación de la Unión Europea (o, al menos, del MRR). La relevancia central de este criterio de aplicabilidad objetivo, financiero y funcional va ser relevante, en los términos que luego se exponen (infra § 45), para argumentar la posible aplicación del RDL-PRTR incluso a Administraciones públicas -como las locales- que no están claramente comprendidas en el ámbito de aplicación subjetivo del Real Decreto-Ley, pero que efectivamente gestionan directa o indirectamente fondos europeos.

32. También desde la perspectiva objetiva, el Real Decreto-Ley 36/2020 no abarca toda la gestión de los fondos europeos NGEU. El art. 1 RDL-PRTR (que es norma básica conforme a la DF 1.1) constriñe la 
REALA. Nueva Época - N.o 16, octubre 2021 - ISSN: 1989-8975 - DOI: https://doi.org/10.24965/reala.i16.10994 - [Págs. 33-52]

Aplicación del régimen administrativo especial de los fondos Next Generation EU a las entidades locales

materia objeto de regulación especial a algunos concretos aspectos de la actuación administrativa, no a toda la gestión administrativa de los fondos europeos. Esta acotación del objeto de regulación, al contenerse en un precepto básico como es el art. 1 RDL-PRTR, impide que las comunidades autónomas (y en segundo grado, las entidades locales) añadan nuevas especialidades de gestión contrarias a los preceptos básicos (o plenos) del propio RDL-PRTR o de las leyes administrativas generales. El hecho de que el RDL-PRTR no haya regulado de forma exhaustiva la gestión administrativa de los fondos europeos no supone que todo lo no regulado expresamente por el RDL-PRTR pueda ser objeto de regulación autonómica especial. Esto es, y por ejemplo, en la medida en que el RDL-PRTR no regula específicamente las encomiendas de gestión, como posible forma de gestión de los fondos europeos, rige tanto para el Estado como para las comunidades autónomas y las entidades locales la regulación actual (básica) del art. 11 LRJSP. El RDL-PRTR simplemente ha acotado una serie de actuaciones, trámites o procedimientos administrativos que considera capitales para una gestión eficiente de los fondos europeos. La gestión administrativa especial de los fondos europeos se define por esas reglas capitales. En esa medida, todo lo no regulado expresamente en el RDL-PRTR se puede considerar que es actuación administrativa ordinaria, y por tanto regulada por las leyes administrativas ordinarias (estatales o autonómicas).

\section{4. Ámbitos subjetivos de aplicación}

33. El ámbito subjetivo de aplicación del Real Decreto-Ley $36 / 2020$ es más complejo de lo que a priori pudiera pensarse. Algunos defectos de técnica normativa dan lugar a resultados parcialmente antinómicos entre su art. 2 y la Disposición final 1. ${ }^{a} .2$. El art. 2 RDL-PRTR define una amplio ámbito de aplicación subjetivo para el conjunto de sus normas: «cualesquiera de las entidades del sector público (...)», aunque al tiempo modula objetivamente ese ámbito amplio de aplicación diferenciando entre los distintos fondos europeos (todos los de NGEU o sólo los del MRR). Pero, junto a este ámbito subjetivo universal del art. 2 RDL-PRTR, la Disposición Final 1. ${ }^{\text {a }}$.2 expresamente establece que «no tienen carácter básico y, por tanto, solo serán de aplicación a la Administración General del Estado y al sector público institucional estatal (...)». Según se ve, la DF 1. a .2 RDL-PRTR aparentemente contradice lo previamente establecido en el art. 2 RDL-PRTR. Esta aparente antinomia se puede resolver mediante varias precisiones de principio.

34. En primer lugar, hay que advertir de que la DF 1. ${ }^{\text {a }} .2$ RDL-PRTR presenta alguna insuficiencia técnica. Porque confunde el ámbito aplicativo de las normas con el título competencial estatal sobre el que descansan. La DF 1.1 RDL-PRTR da a entender que con carácter general el Real Decreto-Ley tiene carácter básico, y por ello sería en principio aplicable a todas las entidades del sector público (estatal, autonómico y local). Este criterio de principio sería coherente con lo previamente establecido en el art. 2 RDL-PRTR. Pero seguidamente, la DF 1. ${ }^{\mathrm{a}} .2 \mathrm{RDL}-\mathrm{PRTR}$ precisa que «no tienen carácter básico y, por tanto, sólo serán de aplicación a la Administración General del Estado y al sector público institucional estatal» una lista larga de preceptos. Todos estos preceptos, por no ser básicos, no serían aplicables ni a las comunidades autónomas ni a las entidades locales.

35. El primer déficit técnico de la DF $10^{a} \cdot 2$ RDL-PRTR está en la propia insuficiencia de la distinción -aparentemente binaria- entre lo básico y lo no básico. Porque, previamente, la propia DF 1.1 RDL-PRTR había identificado varios títulos competenciales para el conjunto del Real Decreto-Ley, no todos básicos. En especial, la competencia estatal ex art. 149.1.14 CE (hacienda general y deuda del Estado) no es básica, sino exclusiva, con lo que los preceptos amparables en ese título competencial (que no precisa el propio RDL-PRTR) serían de aplicación plena, a todo el sector público, y no sólo a la Administración General del Estado y el sector público institucional estatal. En consecuencia, calificar un precepto del Decreto-Ley como «no básico» no implica necesariamente que no sea aplicable a las comunidades autónomas y las entidades locales. Si se concluye que algún precepto concreto del Real Decreto-Ley se apoya en la competencia exclusiva estatal ex art. 149.1.14 CE (lo cual no es fácil, dado el criterio restrictivo de la STC 233/1999, FJ 4) ciertamente será una norma no-básica, pero no por ello inaplicable a las comunidades autónomas y las entidades locales (Prieto, 2021, p. 515).

36. En segundo lugar, que un precepto sea básico no significa que necesariamente vincule a todo el sector público, y por tanto también a las comunidades autónomas y las entidades locales. En ejercicio de una competencia legislativa básica, el Estado tanto puede dictar reglas para todas las Administraciones públicas (y demás entidades instrumentales vinculadas) como sólo para una parte de ellas. Puede el Estado, por ejemplo, dictar normas básicas sólo para la propia Administración estatal; o sólo para la Administración local; o para la Administración estatal y la local, pero no para la autonómica (por ejemplo, en relación con las 
REALA. Nueva Época - N.o 16, octubre 2021 - ISSN: 1989-8975 - DOI: https://doi.org/10.24965/reala.i16.10994 - [Págs. 33-52]

Aplicación del régimen administrativo especial de los fondos Next Generation EU a las entidades locales

Francisco Velasco Caballero

indemnizaciones por servicio de los empleados públicos estatales y locales: art. 2.1 a) y e) del Real Decreto 462/2002, de 24 de mayo). Es lo que ocurre con varios preceptos del Real Decreto-Ley 36/2020 relativos a los PERTE, que se califican en la DF 1. ${ }^{\mathrm{a}} .2$ como básicos, aunque en esos preceptos se regula sólo la actuación de órganos administrativos estatales. En suma, es el propio Estado, en ejercicio de su competencia básica, quien puede decidir el mayor o menor alcance de sus propias bases. Puede el Estado, incluso, aprobar normas básicas que, por propia decisión legislativa estatal, sean desplazables por las comunidades autónomas o por las entidades locales (Font, 2000, p. 235; Velasco, 2009, p. 204). Ya en la actualidad, la legislación estatal de régimen local contiene múltiples excepciones aplicativas, para los municipios de algunas concretas comunidades autónomas. De entrada, en su texto original ya la LBRL preveía algunas excepciones aplicativas en el País Vasco (art. 39 y DA $2 .^{a}$ ), Navarra (DA 3. ${ }^{a}$ ), Cataluña (DA 4. ${ }^{a}$ ), Illes Balears (art. 40), e Islas Canarias (art. 41) (Parejo, 2003, p. 899). Esta opción ha sido pacíficamente aceptada por la jurisprudencia constitucional ${ }^{21}$. En estos casos, es la propia norma básica estatal quien opta por un cierto grado de diversidad, y no por la completa uniformidad, como patrón normativo común en toda España. En otros términos: el «denominador normativo común» establecido por el Estado como norma básica consiste precisamente en abrir algunos espacios a la diversidad, cuando así lo consideren oportuno las correspondientes comunidades autónomas.

37. Por otro lado, es una paradoja de nuestro sistema constitucional, nunca abordado frontalmente por la jurisprudencia constitucional, que la regulación de la Administración General del Estado, que lógicamente sólo puede corresponder al propio Estado, únicamente se puede apoyar en títulos competenciales básicos, los enunciados en el art. 149.1.18 CE. En especial, en la competencia básica sobre el «régimen jurídico de las Administraciones públicas» y en la competencia, también básica, sobre el "procedimiento administrativo común ${ }^{22}$. En consecuencia, y aunque resulte paradójico, la regulación minuciosa y completa de la Administración General del Estado tiene amparo formal en una competencia básica (sic). Esta paradoja constitucional lleva luego a la necesaria distinción, en las leyes administrativas, entre dos tipos de preceptos básicos: Ios aplicables a todas las Administraciones públicas (los «básicos-básicos»); y los aplicables sólo a la Administración General del Estado, preceptos estos últimos a los que las leyes administrativas, con una imprecisión inevitable, califican como «no-básicos» (pero que formalmente sí son básicos, porque se dictan al amparo de una competencia básica). Así ocurre, por ejemplo, en la DF $14 .{ }^{a}$ LRJSP que primero declara (apartado 1) que «esta Ley se dicta al amparo de lo dispuesto en el artículo 149.1.18 de la Constitución Española que atribuye al Estado competencia exclusiva sobre las bases régimen jurídico de las Administraciones Públicas», para seguidamente establecer (apartado 2) que «no tiene carácter básico y se aplica exclusivamente a la Administración General del Estado y al sector público estatal lo previsto en (...)». Esta misma paradoja se encuentra hoy en el RDL-PRTR, donde una buena parte de sus preceptos sobre la gestión administrativa de los fondos europeos se califica por la propia DF 1. ${ }^{\text {a }} 1$ RDL-PRTR como «no básicos», aunque en puridad sólo pueden descansar sobre las competencias básicas estatales ex art. 149.1.18 CE.

\subsection{Interacción entre los criterios objetivos y subjetivos}

38. Más arriba ya se precisó que algunos preceptos del RDL-PRTR modifican de forma universal e intemporal previas leyes administrativas generales (supra § 29), unas aplicables a todas las Administraciones públicas y otras sólo a la Administración del Estado. También se ha explicado que otros preceptos del RDL-PRTR no modifican leyes previas, sino que simplemente excepcionan o desplazan su aplicación en relación con los fondos europeos NGUE, y que esa excepción aplicativa unas veces se refiere a todas las Administraciones públicas y otras veces sólo a la Administración del Estado (supra § 30 ). De esta forma, para cada precepto del Real Decreto-Ley hay que precisar si es un precepto general o especial y, también, si es un precepto que vincula a todas las Administraciones públicas o sólo a la Administración del Estado. De la conjugación de estos dos criterios derivan varios tipos normativos en el RDL-PRTR.

39. Tenemos, en primer lugar, preceptos generales (no confinados a la gestión de los fondos europeos) que rigen para todas las Administraciones públicas. Son aquellos preceptos que modifican de forma definitiva preceptos básicos estatales aplicables a todas las Administraciones públicas. Es el caso, por ejemplo,

21 SSTC 214/1989, FJ 26; 147/1991, FFJJ 4 d) y 5; 109/1998, FJ 3; 50/1999, FJ 6; 132/2012, FJ 3, entre otras.

22 Por todas: STC 50/1999, FJ 3 y STC 55/2018, FJ 6. 
REALA. Nueva Época - N.o 16, octubre 2021 - ISSN: 1989-8975 - DOI: https://doi.org/10.24965/reala.i16.10994 - [Págs. 33-52]

Aplicación del régimen administrativo especial de los fondos Next Generation EU a las entidades locales

de la nueva regulación de los encargos de servicios a medios propios contenida en la DF 5. ${ }^{\mathrm{a}} 1 \mathrm{RDL}-\mathrm{PRTR}$, que modifica con carácter general la norma básica del art. 32.7 b) de la Ley 9/2017, de 8 de noviembre, de Contratos del Sector Público.

40. Un segundo supuesto es el de los nuevos preceptos objetivamente generales (no limitan su campo de aplicación a la gestión de los fondos europeos) pero que sólo rigen para la Administración del Estado. Es el caso de la mayoría de los nuevos plazos del procedimiento de evaluación ambiental, acortados de forma general (para cualquier supuesto, no sólo para los proyectos financiados con fondos europeos) en la DF 3 . $^{a}$ RDL-PRTR.

41. Tenemos, en tercer lugar, nuevas reglas especiales, aplicables a todas las Administraciones públicas, que simplemente desplazan -pero no derogan- previas normas generales y de aplicación a todas las Administraciones públicas. Así, por ejemplo, el art. 39 RDL-PRTR establece hoy la posible tramitación anticipada de expedientes de gasto de ejercicios posteriores (cuando la financiación provenga del MRR o del fondo REACT-EU, aunque no de los demás fondos también integrados en el NGEU). Esta norma, autocalificada como básica por la DF 1. ${ }^{\text {a }} 2$ RDL-PRTR, rige claramente para todas las Administraciones públicas, aunque sólo para la gestión de fondos europeos. Lo mismo se pude decir del plazo extraordinario de ocho días para la presentación de proposiciones en procedimientos abiertos simplificados para la adjudicación de contratos de obras de hasta 80.000 euros (art. 50.1 c) RDL-PRTR), que excepciona el plazo general de 10 días del art. 159.6 LCSP (plazo básico, conforme a la DF 1.3 LCSP). Cuestión problemática es la posible relación entre una nueva norma básica especial del RDL-PRTR y previas normas autonómicas o locales que eran conformes con anteriores bases estatales, pero no con las nuevas. En el caso de las normas locales, esta divergencia supone llanamente la inaplicación de la norma local contraria. En el caso de las normas autonómicas se produce un resultado de inconstitucionalidad sobrevenida de la norma autonómica, que normalmente no da lugar a la simple inaplicación de la norma autonómica ${ }^{23}$, salvo que la norma autonómica fuera en sí una simple reproducción de una norma básica anterior (STC 102/2016, FJ 6).

42. Finalmente, en el RDL-PRTR hay nuevas reglas administrativas especiales (sólo aplicables a la gestión de fondos europeos) que sólo vinculan a la Administración del Estado. Aquí se cuentan diversas normas sobre la "gobernanza» del PRTR o específicamente sobre los PERTE que tienen por destinataria directa, expresa y única a la Administración del Estado. Así, por ejemplo, el art. 13 RDL-PRTR regula la aprobación del PRTR por el Consejo de Ministros. Este precepto, aunque se califica como «básico» por la DF 1. ${ }^{a}$.2 RDL-PRTR, no produce ningún efecto directo sobre las comunidades autónomas o los gobiernos locales. Igualmente, el art. 46.1 RDL-PRTR, que se califica como básico en la DF $1 .{ }^{a} .2$, establece que «las entidades del sector público estatal promoverán la modificación del correspondiente sistema de información contable (...)». Es evidente que este precepto, aun siendo nominalmente básico, limita su aplicación a sólo el sector público estatal. A estos supuestos se equiparan otros que la propia DF 1. ${ }^{\mathrm{a}}$.2 RDL-PRTR califica como «no básicos», calificación esta que en realidad nada dice del título competencial del Estado, sino de la aplicabilidad del precepto a sólo la Administración del Estado (supra § 36). En relación con los dos grupos de normas (las «básicas» pero sólo aplicables a la Administración estatal y las autocalificadas como «no básicas») se plantea entonces si, a falta de regulación autonómica simétrica, aquellas reglas especiales de gestión administrativa son de aplicación supletoria a las comunidades autónomas y a las entidades locales (infra $\S 45)$. Piénsese, por ejemplo, en el art. 59.1 c) RDL-PRTR, que establece que los convenios administrativos, como forma de ejecución del PRTR, pueden tener una duración máxima de 6 años (prorrogables por otros 6). Esta norma se califica por la DF 1. ${ }^{\text {a }} 2$ como «no básica» y por tanto sólo sería aplicable a los convenios donde es parte la Administración General del Estado. Lo cierto es que ese plazo especial y «no básico» de 6 años desplaza -solo para la gestión de los fondos europeos- el plazo básico de 4 años del art. 4 h) 1 LRJSP (plazo básico que rige para todos los convenios administrativos, salvo regulación normativa específica). La cuestión es, entonces, que conforme al RDL-PRTR los convenios estatales para la ejecución de los fondos europeos NGEU pueden tener una duración de 6 años, mientras que los convenios autonómicos o locales para la gestión de esos mismos fondos europeos sólo pueden durar 4 años (salvo normativa especial). Este resultado es paradójico, y no resulta coherente con la opción del Reglamento UE 2021/241 a favor de una efectiva ejecución de los fondos europeos (MRR).

43. En términos cuantitativos son pocas las normas especiales y «no básicas» del RDL-PRTR que desplazan normas previas de aplicación general y donde, por tanto, se da la paradoja de que, para la gestión

23 SSTC STC 1/2003, FJ 8, con una doctrina por ahora estable: SSTC 66/2011, FJ 5; 187/2012, FJ 5: $177 / 2013$, FJ 8. 
REALA. Nueva Época - N.o 16, octubre 2021 - ISSN: 1989-8975 - DOI: https://doi.org/10.24965/reala.i16.10994 - [Págs. 33-52]

Aplicación del régimen administrativo especial de los fondos Next Generation EU a las entidades locales

de los mismos fondos europeos, el Estado dispone de reglas de gestión más favorables que las comunidades autónomas y las entidades locales. Con carácter general, las normas «no básicas» del RDL-PRTR desplazan -para la gestión de los fondos europeos- previas normas generales (en su objeto) pero también «no básicas» (sólo aplicables a la Administración del Estado). Así ocurre, por ejemplo, en materia de subvenciones, donde las normas especiales de justificación de las subvenciones (art. 63 RDL-PRTR) desplazan la aplicación de previas normas «no básicas» del Reglamento General de Subvenciones (por ejemplo, los arts. 72 y 75 del Real Decreto 887/2006, de 21 de julio). Lo mismo se puede decir de la evaluación ambiental de proyectos estatales vinculados al PRTR (regulada en el art. 66 RDL-PRTR), que desplaza la aplicación de previos preceptos «no básicos» (así declarados por la DF 8. ${ }^{a} 2$ de la Ley 21/2013) aplicables sólo al Estado. Esas normas estatales «no básicas» (y ahora desplazadas por las normas también «no básicas» del RDL-PRT) eran aplicables, ya antes de la pandemia, de forma supletoria en todas aquellas comunidades autónomas y entidades locales en las que no rigieran otras reglas propias. La cuestión es ahora si -y en qué medida- las nuevas reglas «no básicas» del RDL-PRTR son de aplicación supletoria en la gestión autonómica y local de los fondos europeos. En mi opinión, la respuesta debe ser diferenciada. Como sigue.

\section{APLICACIÓN SUPLETORIA DEL RDL-PRTR}

44. Según se ha expuesto, una parte importante del RDL-PRTR sólo es aplicable a la Administración del Estado y su sector público institucional. Se trata de dos tipos de preceptos. Están, en primer lugar, aquellas normas que la DF 1.2 RDL-PRTR considera básicas, pero que en su propia redacción se refieren directa y exclusivamente a la Administración del Estado. Y están, en segundo lugar, aquellos otros preceptos que la propia DF 1.2 RDL-PRTR califica como «no básicos». En relación con ambos grupos de preceptos hay que plantearse su posible aplicación supletoria a las comunidades autónomas y las entidades locales, cuando actúen en el marco del PRTR para la ejecución de fondos europeos (Font, 2021, p. 122).

45. Como es sabido, la supletoriedad es una técnica de integración de lagunas normativas, no es en ningún caso un título competencial estatal. Esto es, fuera de sus competencias materiales, el Estado no puede dictar norma alguna, ni siquiera meramente supletoria. Este significado de la supletoriedad como técnica de integración de lagunas normativas es la única que admite hoy el art. $149.3 \mathrm{CE}^{24}$, que establece que el Derecho estatal es «en todo caso» supletorio del Derecho autonómico. En ocasiones, en la doctrina se ha propuesto una comprensión restrictiva de esta técnica de integración normativa (y por tanto del propio art. 149.3 CE). Se ha dicho, en este sentido, que la supletoriedad del Derecho estatal a la que se refiere el art. 149.3 CE sólo afecta a las comunidades autónomas, pero no a otras organizaciones públicas (Borrajo, 2018, p. 1532; Rodríguez de Santiago, 2021, p. 806 § 67) y por tanto no a las entidades locales. También se ha dicho que la supletoriedad es una técnica más de integración normativa, sin precedencia respecto de otras, como la analogía (se entiende que la analogía naturalmente propicia la auto-integración del ordenamiento autonómico en el que se presenta la laguna [Muñoz Machado, 2015, p. 284 § 933; Rodriguez de Santiago, 2021, p. 808 § 71]). En mi opinión, ninguna de las dos comprensiones restrictivas del art. 149.3 CE cuenta con argumentos determinantes.

46. A mi juicio, el hecho de que el art. 149.3 CE se refiera a la supletoriedad del Derecho estatal sólo respecto del autonómico no permite excluir la supletoriedad del Derecho estatal también respecto del Derecho local. La omisión de toda referencia expresa al Derecho local en el art. 149.3 CE tiene que ver, simplemente, con que en su conjunto el art. 149.3 CE sólo articula (mediante la cláusula residual de competencia estatal, la prevalencia y la supletoriedad) los dos ordenamientos que se encuentran en posición de igualdad competencial formal: el estatal y los autonómicos. El ordenamiento propio de cada entidad local (el contenido en ordenanzas y reglamentos locales) es -en clave constitucional- siempre de segundo nivel, respecto del estatal o los autonómicos. Cada ordenamiento local está simplemente asegurado en su posible existencia por la garantía constitucional de autonomía local (Velasco y Castillo, 2021, p. 88 § 69), pero no se encuentra en posición de igualdad respecto de los ordenamientos estatal y autonómicos. En consecuencia, una vez afirmada expresamente por el art. 149.3 CE la supletoriedad del Derecho estatal (respecto del autonómico) carece de sentido sistemático que el Derecho de cada entidad local (en la medida en que está subordinado al Derecho estatal o al autonómico) cuente con criterios de integración propios y distintos de los que articu-

24 STC 118/2016, FFJJ 6-7 y 61/1997, FJ 12 c). 
REALA. Nueva Época - N.o 16, octubre 2021 - ISSN: 1989-8975 - DOI: https://doi.org/10.24965/reala.i16.10994 - [Págs. 33-52]

Aplicación del régimen administrativo especial de los fondos Next Generation EU a las entidades locales

Francisco Velasco Caballero

lan la relación entre el ordenamiento estatal y los autonómicos. Dado que el Derecho estatal y los Derechos autonómicos -cada uno en sus límites competenciales- pueden impedir las lagunas de los ordenamientos locales (dictando normas de aplicación directa o con eficacia meramente supletoria) una laguna normativa local es, en última instancia, también un defecto de regulación del Estado o de la Comunidad Autónoma. Y por lo mismo, tiene sentido aplicar aquí también la supletoriedad del Derecho estatal a la que se refiere el art. 149.3 CE.

47. En segundo lugar, afirmar que cada órgano aplicativo (administrativo o judicial) puede integrar una laguna normativa autonómica o local mediante diversas técnicas disponibles (en especial, mediante la analogía) sin necesidad de acudir primeramente al Derecho positivo estatal, es un enunciado de principio que no tiene sustento constitucional directo y, además, supone una comprensión restrictiva del art. 149.3 CE. La STC 118/1996 ciertamente habla de «los medios usuales de interpretación del derecho», pero sólo para la identificación de lagunas normativas, no para su integración (FJ 6). Además, la comprensión doctrinal restrictiva de la supletoriedad estatal presupone una alta independencia sistemática de cada ordenamiento (el estatal, los autonómicos y los locales) y la consiguiente preferencia por la autointegración de sus lagunas (Leguina, 1997, p. 18), para lo que sin duda que es adecuada la analogía. Sin embargo, la realidad constitucional mitiga mucho esa imagen dogmática de ordenamientos diferenciados y auto-integrados (Borrajo, 2018, p. 1536). Los ordenamientos autonómicos contienen numerosas normas cuya validez, alcance y sentido se define por normas básicas estatales (que actúan cómo cánones indirectos de constitucionalidad de las normas autonómicas). Las ordenanzas municipales son, en la mayoría de los casos, desarrollos reglamentarios de previas leyes (o reglamentos) estatales o autonómicos; no se pueden aprobar directamente en materias reservadas a la ley, y están vinculados jerárquicamente a las leyes e incluso, en ocasiones, a los reglamentos estatales o autonómicos (Velasco y Castillo, 2021, p. 98 § 115). En este contexto de intensa interacción de ordenamientos territoriales tiene sentido que la supletoriedad del Derecho estatal, a la que se refiere el art. 149.3 CE sea tomado en todo su posible alcance normativo. Esto es, como forma primaria de integración de lagunas (en los Derechos autonómicos y locales) y no como una simple técnica disponible -entre otras- para resolver déficits normativos. Esta aplicación supletoria primaria del Derecho estatal está muy presente en la jurisprudencia contenciosa, tanto urbanística ${ }^{25}$ como de empleo público (donde la aplicación supletoria de leyes y reglamentos estales «no básicos» es cotidiana) ${ }^{26}$.

48. Una vez argumentado el amplio margen potencial para la supletoriedad del Derecho estatal, hay que plantearse en qué medida los diversos preceptos del RDL-PRTR no aplicables directamente a las entidades locales pueden ser objeto de aplicación supletoria. Obviamente, la posible supletoriedad del Real Decreto-Ley 36/2020 solo es planteable allí donde no hay norma autonómica o local propia. Precisamente la cuestión más compleja y cuestionable en torno a la supletoriedad es la identificación de cuándo estamos verdaderamente ante una laguna normativa, pues con frecuencia la laguna no es patente, sino que resulta de cómo se interpreten la normas (Larenz, 1991, p. 370). En ocasiones, lo que parece una laguna bien puede ser la opción política de no regular (Leguina, 1997, p. 17); o la opción de no dictar una norma especial, para que se aplique una norma general.

49. En relación con el Real Decreto-Ley 36/2020, su posible aplicación supletoria a las comunidades autónomas y las entidades locales depende de en qué medida se considere que la gestión de los fondos europeos NGEU es una actividad administrativa propiamente singular y especial, y por tanto demandante de una regulación también especial (o, en su defecto, de la aplicación supletoria de las normas especiales que rigen esa actividad para la Administración del Estado). En relación con esto hay que señalar que, en su mayor parte, el Real Decreto-Ley 36/2020 no regula inmediatamente la Administración pública, ni el sector público. Regula la gestión administrativa de ciertos fondos europeos (los que menciona en el art. 2). Se puede decir, de forma más descriptiva, que el objeto propio y característico del RDL-PRTR es la recuperación económica post-covid mediante la gestión administrativa de fondos europeos. EI RDL-PRTR no tiene por objeto propio ni las subvenciones, ni la intervención del gasto, ni la contratación pública, ni los consorcios. El objeto de regulación es la recuperación económica mediante la gestión administrativa de los fondos europeos. Es una regulación especialmente adaptada a la estrategia, condiciones y reglas temporales de los Reglamentos (UE) 2020/2094 y 2021/241. Esto es, el carácter netamente sectorial, especial, fugaz y coyuntural de los fon-

25 SSTS de 13 de febrero de 2003, RC 9491/1998; 30 de junio de 2006, RC 1900/2003; 14 de diciembre de 2009, RC 293/2006; 25 de mayo de 2011, RC 5136/2007; 23 de octubre de 2014, RC 403/2014.

26 En relación con el Real Decreto 33/1986, de 10 de enero, por el que se aprueba el Reglamento de Régimen Disciplinario de los Funcionarios de la Administración del Estado: STS 548/2017, de 30 de marzo (ES:TS:2017:1455). 
REALA. Nueva Época - N.o 16, octubre 2021 - ISSN: 1989-8975 - DOI: https://doi.org/10.24965/reala.i16.10994 - [Págs. 33-52]

Aplicación del régimen administrativo especial de los fondos Next Generation EU a las entidades locales

Francisco Velasco Caballero

dos europeos regulados en los reglamentos IRUE y MRR también confiere un sentido coyuntural y especial a la gestión administrativa (nacional) de los fondos europeos. De esta manera, la gestión administrativa de los fondos europeos se presenta como un sector o ámbito de la realidad reconducible a varios títulos competenciales estatales (normalmente básicos ex art. 149.1.18 CE), autonómicos (de desarrollo de las bases estatales, fundamentalmente) o locales (fundamentalmente, en virtud de la potestad de autoorganización del art. 4.1. a) LBRL). A partir de esta identificación de la singular materia regulada en el RDL-PRTR se puede considerar la posibilidad de que en determinados aspectos de la gestión autonómica y local de los fondos europeos pueda haber un verdadero déficit de regulación que llame a la aplicación supletoria de preceptos del RDL-PRTR sólo aplicables de forma directa a la Administración del Estado. Esta labor de identificación e integración de lagunas sólo puede hacerse de forma muy selectiva y caso por caso. Hecha esta advertencia general, y en correspondencia con la tipología de ámbitos de aplicación expuesta más arriba (supra § 38), ahora hay que considerar varios supuestos.

50. Tenemos, en primer lugar, el caso de las normas generales (no limitadas a la gestión de los fondos europeos) sólo aplicables de forma directa a la Administración del Estado. Así ocurre cuando el RDL-PRTR da nueva redacción a algunos preceptos «no básicos» preexistentes, que de esta forma quedan derogados. Es el caso de la DF 2. ${ }^{a}$ RDL-PRTR que modifica la redacción del vigente art. 48.8 LRJSP sobre la formalización y publicación de los convenios de la Administración General del Estado (haciendo ahora preceptiva en todo caso la publicación en el BOE). No estamos ahora ante una norma especial (para los proyectos financiados con fondos europeos) sino ante una nueva norma general, aunque sólo para los convenios de la Administración General del Estado. En la medida en que el anterior art. 48.8 LRJSP era aplicable de forma supletoria a todos los convenios administrativos, allí donde no había regulación autonómica específica, ahora también la nueva redacción del art. 48.8 RDL-PRTR tendrá eficacia supletoria, y por tanto será obligatoria -en defecto de norma autonómica en sentido contrario- para todos los convenios administrativos autonómicos o locales.

51. En lo que hace a la aplicación supletoria de las normas administrativas especiales del RDL-PRTR (sólo dirigidas a la gestión de los fondos europeos) pero aplicables sólo a la Administración del Estado, es necesario distinguir dos supuestos: cuando la nueva regulación exceptúa para el Estado una previa norma básica; y cuando la nueva norma no desplaza ningún precepto básico anterior.

a) No hay aplicación supletoria de normas especiales y «no básicas» del Real Decreto-Ley 36/2020 cuando anteriormente ya existía una norma básica vinculante para todas las Administraciones públicas, y ahora el RDL-PRTR excepciona su aplicación sólo a la Administración General del Estado (mediante una norma «no básica»). Aquí no hay propiamente una laguna, ya que la norma básica previa sigue vigente para las comunidades autónomas y las entidades locales. Y por lo mismo, no hay supletoriedad que active ex art. 149.3 la aplicación de la nueva norma «no básica» del RDLPRTR. Así ocurre, por ejemplo, con el art. 48.1 RDL-PRTR, que declara la «tramitación de urgencia y el despacho prioritario» de los expedientes administrativos que impliquen gastos de fondos europeos. Este carácter urgente y prioritario de los expedientes con fondos europeos desplaza -sólo para la Administración del Estado- la aplicación de las normas básicas contenidas en los arts. 33 y 71 LPAC, que respectivamente exigen la declaración expresa y previa de la declaración de tramitación urgente y el despacho por orden de incoación de los expedientes de naturaleza homogénea. Pero precisamente por ser la del art. 48.1 RDL-PRTR una regulación «no básica», no desplaza la aplicación de la LPAC a las comunidades autónomas y las entidades locales. Esta situación es sin duda criticable con carácter general, pues supone que el Estado excepciona para sí las normas básicas que impone a las comunidades autónomas y las entidades locales (Baño, 2004, pp. 17351764). También desde la lógica de los fondos europeos es un resultado paradójico, pues supone la existencia de diversos regímenes jurídicos para la gestión de un mismo fondo (e incluso de un mismo proyecto objeto de ejecución multinivel).

b) Tampoco hay posible supletoriedad del Real Decreto-Ley 36/2020 cuando para una concreta actuación administrativa existía una norma básica estatal específica para las entidades locales, siendo así que ahora el RDL-PRTR establece una norma diferente y "no básica» (por tanto, sólo para la Administración del Estado). Así ocurre, por ejemplo, con el régimen de transferencias de créditos presupuestarios en el art. 179 LHL, aplicable solo a las entidades locales (Martínez Sánchez, 2021, p. 410 § 64) disonante del régimen de transferencias de créditos entre secciones dentro del presupuesto general del Estado (art. 38 RDL-PRTR). En la medida en que el art. 179 LHL establece una norma «básica» (según los criterios competenciales generales de la STC 233/1999) no hay laguna 
REALA. Nueva Época - N.o 16, octubre 2021 - ISSN: 1989-8975 - DOI: https://doi.org/10.24965/reala.i16.10994 - [Págs. 33-52]

Aplicación del régimen administrativo especial de los fondos Next Generation EU a las entidades locales

alguna que deba ser integrada y por tanto no hay causa para una aplicación supletoria del art. 38 RDL-PRTR. Y lo mismo se puede decir del régimen de fiscalización previa del gasto financiado con los fondos NGEU, que se hará siempre en régimen de requisitos básicos (art. 45. 1 RDL-PRTR). Este precepto, que es especial respecto de la norma general del art. 150.2 b) LGP (sólo aplicable al presupuesto general del Estado) no puede aplicarse supletoriamente a los expedientes de gasto locales, pues cuentan con una regulación (básica) en el art. 219.2 LHL.

c) La supletoriedad sí es en principio posible en relación con normas especiales y «no básicas» del RDLPRTR que contienen normas verdaderamente novedosas, referidas a cuestiones que no estaban ya previamente reguladas en normas básicas estatales. Así, por ejemplo, para la provisión de puestos de trabajo directamente vinculados a la gestión de los fondos europeos, el art. 30.3 RDL-PRTR (precepto «no básico» conforme a su DF 1. ${ }^{a}$.2) establece como modos preferentes la redistribución de efectivos, la reasignación de efectivos y la atribución temporal de funciones. Es esta una regulación específica e innovadora para la gestión de los fondos europeos que, en la medida en que no corrige ninguna norma previa del EBEP y no afecta a otras normas autonómicas o locales precedentes, es aplicable de forma supletoria a las entidades locales. Lo mismo se pude decir de la «asignación de funciones a tiempo parcial» del personal funcionario (para tareas de gestión de los fondos europeos) regulada en el art. 31.1 RDL-PRTR. También, en relación con los convenios para la ejecución del PRTR con fondos europeos, se puede considerar de aplicación supletoria su tramitación anticipada (respecto de ejercicio presupuestario en el que se formaliza el convenio), previsión normativa «no básica» del art. 59.3 RDL-PRTR. Por último, también se puede considerar la aplicación supletoria de la norma que excluye la evaluación de impacto ambiental para las obras de modernización de instalaciones existentes, cuando se realicen con fondos europeos (art. 66 RDL-PRTR). Es este un precepto «no básico» que precisa el alcance de una previa norma «no básica» ya vigente (el art. 8.3 de la Ley 21/2013, de 9 de diciembre, de Evaluación Ambiental, referido a la reparación o mejora de «infraestructuras críticas») y por tanto no aplicable directamente a las comunidades autónomas y las entidades locales. Pues bien, en la medida en que este último precepto no hubiera tenido su correspondiente réplica en leyes autonómicas de desarrollo, sería ya actualmente una norma de aplicación supletoria (por las Administraciones autonómicas y locales). Obviamente, hay normas «no básicas» y propiamente nuevas del RDL-PRTR que en ningún caso son susceptibles de aplicación supletoria a las entidades locales, por su manifiesta ajeneidad o inidoneidad. Así, por ejemplo, la composición de la Comisión para la Recuperación, Transformación y Resiliencia, que integra a varios altos cargos del Gobierno y de la Administración estatal (art. 14 RDL-PRTR) es una regulación por completo ajena a la gestión local de los fondos europeos, y por tanto inaplicable supletoriamente.

\section{APLICACIÓN SUPLETORIA DEL DERECHO AUTONÓMICO PARA LA EJECUCIÓN LOCAL DE LOS FONDOS EUROPEOS}

52. Ya se dijo más arriba (supra § 15) que diversas comunidades autónomas han aprobado reglamentos, decretos-leyes y leyes para la agilización administrativa relacionada con los fondos europeos NGEU. Se plantea entonces, al igual que ya se ha hecho con el RDL-PRTR, si los preceptos autonómicos nuevos o especiales sobre los fondos europeos son también aplicables a las entidades locales, en la medida en que sobre ellas descanse la ejecución de concretos proyectos o inversiones. Así, por ejemplo, según el art. 7.5 del Decreto-Ley extremeño 3/2021, los puestos de trabajo que compongan las «unidades administrativas provisionales» se amortizan de forma automática, «sin necesidad de trámite alguno» una vez concluido el proyecto financiado con fondos europeos. Este precepto no tiene correspondencia en el RDL-PRTR (por lo que para el Estado rige el criterio general de supresión por decisión expresa que se deduce de los arts. 69.2 y 74 EBEP) y sólo se aplica directamente a la propia Administración autonómica -no a las entidades locales extremeñas- conforme al art. 2 del propio Decreto-Ley extremeño. Resulta, además, que conforme al art. 78.2 EBEP la supresión de los puestos de trabajo se debe regular por «leyes de función pública», lo que impide la regulación directamente local. Dado que la Ley extremeña 13/2015, de 8 de abril, de Función Pública, ni prevé ni regula la amortización automática de puestos de trabajo, surge la duda de si, en el caso de que un ayuntamiento extremeño crease una «unidad administrativa provisional» con determinados puestos de trabajo, la extinción del correspondiente proyecto con financiación europea supondría, de forma automática, la amortización de los correspondientes puestos de trabajo. 
REALA. Nueva Época - N.o 16, octubre 2021 - ISSN: 1989-8975 - DOI: https://doi.org/10.24965/reala.i16.10994 - [Págs. 33-52]

Aplicación del régimen administrativo especial de los fondos Next Generation EU a las entidades locales

53. En mi opinión, en casos como el planteado, la regulación autonómica puede ser aplicada supletoriamente a las entidades locales, siempre que se den las siguientes circunstancias: que se pueda considerar que existe una verdadera laguna normativa; que no haya regulación propiamente local (por simple inexistencia o porque existe una reserva de ley, lo que impide la regulación local directa [Ortega, 2014, p. 254]); que no exista regulación estatal directamente aplicable (un precepto básico o pleno); y que la regulación autonómica regule un supuesto semejante o simétrico al que se plantea ante una Administración local. Es cierto que la supletoriedad del Derecho autonómico no viene impuesta por ninguna regla constitucional (como sí hace el art. 149.3 CE para el Derecho estatal), pero también es cierto que ante una verdadera laguna normativa -y en defecto de norma estatal supletoria- la norma autonómica puede ser idónea para la integración de la laguna. Sobre todo, por el limitado acervo normativo de cada entidad local con el que proceder a autointegrar la laguna normativa local.

54. En el ejemplo sugerido más arriba (la amortización automática de puestos de trabajo) la cuestión verdaderamente determinante (y no por completo clara) consiste en precisar si existe una laguna de regulación. Esto es, si admitida la posibilidad de crear «unidades administrativas provisionales» en los ayuntamientos (y la adscripción a ellos de concretos puestos de trabajo) falta una regulación expresa sobre la forma de extinción de esos puestos en unidades provisionales. Como ya se ha dicho, el régimen general de empleo público local en Extremadura no contempla ninguna forma de amortización automática de puestos de trabajo. En cambio, para la ejecución de fondos europeos con unidades provisionales de la propia Administración extremeña esa amortización actúa ex lege (art. 7.5 del Decreto-Ley extremeño 3/2021). Se puede considerar que hay aquí un déficit de regulación, porque la posible creación de unidades provisionales locales no va acompañada de regla alguna sobre el destino de los puestos de trabajo de esa unidad, una vez concluida su tarea. Concluir que esa falta de regulación supone la aplicación del régimen general de los puestos de trabajo (esto es, que se crean y extinguen por decisiones administrativas expresas) no casa bien con la naturaleza provisional de la unidad administrativa y de sus puestos de trabajo. Puede considerarse, en esa medida, una situación sin regulación predeterminada. Una laguna colmable con la regla especial de amortización automática que, para el mismo supuesto en la Administración autonómica, expresamente establece el art. 7.5 del Decreto-ley extremeño 3/2021.

55. Puede plantearse también, como hipótesis, la posibilidad de que sobre algún aspecto de la gestión local de fondos europeos exista una norma especial sólo aplicable a la Administración estatal (esto es, una norma calificada como «no básica» por la DF 1. ${ }^{\text {a }}$.2 RDL-PRTR o una norma básica pero que auto-restringe su aplicación a sólo la Administración estatal [supra §§ 40 y 42]) y que para la misma cuestión exista también una norma especial autonómica sólo aplicable a la propia Administración autonómica. En tal supuesto, una posible laguna jurídica para la gestión local de los fondos europeos encontraría -siempre que efectivamente estuviéramos ante una laguna normativa- dos normas susceptibles de ser aplicadas supletoriamente (la norma especial estatal y la norma especial autonómica). A mi juicio, una situación como esta debe resolverse invocando el art. 149.3 CE, que directamente opta por la norma estatal (supletoria).

\section{REFERENCIAS BIBLIOGRÁFICAS}

Alonso García, R. (2012). Sistema jurídico de la Unión Europea (3. ${ }^{a}$ edición). Civitas Thomson Reuters.

Arzoz Santiesteban, X. (25 de noviembre de 2016). La interpretación conforme como técnica de coordinación entre ordenamientos [ponencia]. En Seminario de Teoría y Método del Derecho Público. Zaragoza.

Baño León, J. M. (2004). La vinculación del Estado a las normas básicas de contratación: la prohibición de derogación singular de las bases. En R. Gómez-Ferrer Morant (coord.), Comentario a la Ley de contratos de las Administraciones públicas (pp. 1753-1764), Civitas.

Borrajo Iniesta, I. (2018). El orden constitucional de competencias y de ordenamientos. En M. Rodríguez-Piñero y M. E. Casas Baamonde (dirs.), Comentarios a la Constitución (pp. 1508-1539), Wolters Kluwer, BOE y Tribunal Constitucional.

Bustos Pretel, G. (2021). Ante el ensayo de simplificación y agilidad administrativa por decreto. En M. C. Campos Acuña (dir.), La gestión de los fondos Next Generation (pp. 217-269). La Ley Wolters Kluwer.

Calvo López, S. (2020). Impacto del programa Next Generation EU en España: condicionalidad, retos y oportunidades de un acuerdo histórico. Revista Administración y Ciudadanía, 15, 441-476. https://doi.org/10.36402/ac.v15i2.4616

Colás Tenas, J. (2021). Los gobiernos locales intermedios en la gestión de los fondos europeos para la recuperación. Cuadernos de Derecho Local, 55, 37-51. https://www.gobiernolocal.org/publicaciones/2021/QDL55/QDL55_02_ Jesus_Colas.pdf 
REALA. Nueva Época - N.o 16, octubre 2021 - ISSN: 1989-8975 - DOI: https://doi.org/10.24965/reala.i16.10994 - [Págs. 33-52]

Aplicación del régimen administrativo especial de los fondos Next Generation EU a las entidades locales

Francisco Velasco Caballero

Domínguez Martín, M. (2021). Municipios: competencias y potestades. En F. Velasco Caballero (dir.), Tratado de Derecho Local (pp. 332-356). Marcial Pons.

Font i Llovet, T. (2000). La Carta Municipal de Barcelona en la reforma del régimen local. Justicia Administrativa, extraordinario 2000, 231-242.

Gimeno Felíu, J. M. (2021). De las ideas a la acción en la gestión de los fondos europeos: reflexiones propositivas para el diseño de una adecuada gobernanza en su ejecución. Cuadernos de Derecho Local, 55, 82-114. https://www. gobiernolocal.org/publicaciones/2021/QDL55/QDL55_04_J_M_Gimeno.pdf

Izquierdo Sans, C. (2021). EU y Covid-19: la gobernanza de Europa por la Unión Europea. En F. Velasco Caballero y B. Gregoraci Fernández (coords.), Derecho y política ante la pandemia: reacciones y transformaciones. Tomo I: Reacciones y Transformaciones en el Derecho Público, [Número extraordinario del Anuario de la Facultad de Derecho de la Universidad Autónoma de Madrid] (pp. 443-455). BOE.

Larenz, K. (1991). Methodenlehre der Rechtswissenschaft (6. ${ }^{a}$ ed.). Springer Verlag.

Leguina Villa, J. (1997). El principio de competencia y la supletoriedad del Derecho estatal. Cuadernos de Derecho Público, 2, 9-24. https://revistasonline.inap.es/index.php/CDP/article/view/464

Marco Peñas, E. (2021). Derecho en y tras la pandemia. Los mecanismos de apoyo de la UE para hacer frente a la crisis de la Covid-19: el alcance de la solidaridad entre Estados miembros de la UE. En F. Velasco Caballero y B. Gregoraci Fernández (coords.), Derecho y política ante la pandemia: reacciones y transformaciones. Tomo I: Reacciones y Transformaciones en el Derecho Público [Número extraordinario del Anuario de la Facultad de Derecho de la Universidad Autónoma de Madrid] (pp. 355-373). BOE.

Martínez Fernández, J. M. (2021). Los fondos comunitarios y el Real Decreto-Ley 36/2020 de medidas urgentes para la modernización de la Administración y para la ejecución del plan de recuperación. Su gestión por las entidades locales. Consultor de los Ayuntamientos y de los Juzgados, 5/2021.

Martínez Sánchez, C. (2021). Gasto público. En F. Velasco Caballero (dir.), Tratado de Derecho Local (pp. 389-426), Marcial Pons.

Ministerio de Industria, Comercio y Turismo (2021), Memoria descriptiva PERTE para el desarrollo del vehículo eléctrico y conectado, 2021. https://www.mincotur.gob.es/es-es/gabineteprensa/notasprensa/2021/documents/ memoria\%20descriptiva\%20perte\%20vec.pdf

Montes Sebastián, B. (2021). PERTE y otras fórmulas de colaboración público-privada para la gestión de fondos europeos. En M. C. Campos Acuña, (dir.), La gestión de los fondos Next Generation (pp. 513-549). La Ley Wolters Kluwer.

Muñoz Machado, S. (2015). Tratado de Derecho administrativo y de Derecho público general, Tomo IV. EI ordenamiento jurídico (4. ${ }^{a}$ edición), BOE. https://www.boe.es/biblioteca_juridica/publicacion.php?id=PUB-PB2015-67\&tipo=L\&modo=2

Ortega Bernardo, J. (2014). Derechos fundamentales y ordenanzas locales. Marcial Pons.

Ortega Jiménez, P. (2021). Especialidades de gestión y control presupuestario. Revista de Estudios Locales CUNAL, $238,40-55$.

Parejo Alfonso, L. (2003). La cuestión de la organización del gobierno y la administración insulares en la Comunidad Autónoma de las Islas Baleares. Revista de Estudios de la Administración Local, 291, 891-923. https://doi. org/10.24965/reala.vi291.9200

Pastor Merchante, F. (2017). Las ayudas locales a las empresas. En F. Velasco Caballero (dir.), Tratado de Derecho Económico Local (pp. 297-318), Marcial Pons.

Pazos Vidal, S. (2021). El Plan de Recuperación de la Unión Europea. Oportunidades para las Administraciones locales. Anuario de Derecho Municipal, 14, 49-87. https://doi.org/10.37417/ADM/14-2020_02

Prieto Romero, C. (2021). Las medidas urgentes de modernización de la Administración pāra la ejecución del Plan de Recuperación, Transformación y Resiliencia y su aplicación a las entidades locales. En Anuario del Gobierno Local 2020, (pp. 499-535). Fundación Democracia y Gobierno Local e Institut de Dret Public.

Rodríguez de Santiago, J. M. (2021). Sistema de fuentes del Derecho administrativo. En J. M. Rodríguez de Santiago, G. Doménech Pascual y L. Arroyo Jiménez (coords.), Tratado de Derecho administrativo, Vol. I: Introducción. Fundamentos (pp. 766-860), Marcial Pons.

Sánchez-Barrueco, M. L. (2021). El nuevo marco presupuestario de la Unión Europea para la recuperación postpandemia. Revista de Derecho Comunitario Europeo, 69, 555-599. https://doi.org/10.18042/cepc/rdce.69.03

Velasco Caballero, F. (2009). Derecho local. Sistema de fuentes. Marcial Pons.

Velasco Caballero, F. y Castillo Abella, J. (2021). Fuentes del Derecho Local. En F. Velasco Caballero (dir.), Tratado de Derecho Local (pp. 73-105), Marcial Pons.

Villasalero Díaz, M. (2021). Desafíos y oportunidades en la gestión y control de los fondos europeos para la recuperación Next Generation EU. Consultor de los Ayuntamientos y los Juzgados, Extra 1/2021, 220-229. 